\title{
Characterization of the Diurnal Cycle of the West African Monsoon around the Monsoon Onset
}

\author{
Benjamin Sultan and Serge Janicot \\ IRD, LOCEAN/IPSL, Université Pierre et Marie Curie, Paris, France \\ PhILIPPE DROBINSKI \\ CNRS, SA/IPSL, Université Pierre et Marie Curie, Paris, France
}

(Manuscript received 14 July 2006, in final form 27 November 2006)

\begin{abstract}
This study investigates the diurnal cycle of the West African monsoon and its seasonal modulation with particular focus on the monsoon onset period. A composite analysis around the monsoon onset date is applied to the 1979-2000 NCEP-DOE reanalysis and 40-yr ECMWF Re-Analysis (ERA-40) at 0000, 0600, 1200 , and 1800 UTC. This study points out two independent modes describing the space-time variability of the diurnal cycle of low-level wind and temperature. While the first mode appears to belong to a gradual and seasonal pattern linked with the northward migration of the whole monsoon system, the second mode is characterized by more rapid time variations with a peak of both temperature and wind anomalies around the monsoon onset date. This latter mode is connected with the time pattern of a nocturnal jet reaching its highest values around the onset date.

The diurnal cycle of dry and deep convection is also investigated through the same method. A distinct diurnal cycle of deep convection in the ITCZ is evidenced with a peak at 1200 UTC before the monsoon onset, and at 1800 UTC after the monsoon onset. Strong ascending motions associated with deep convection may generate a gravity wave that propagates northward and reaches the Saharan heat low region $12 \mathrm{~h}$ later. The diurnal cycle of the dry convection in the Saharan heat low is similar during the preonset and the postonset periods with a peak at night (0000 UTC) consistent with the nocturnal jet intensification. This convection is localized at $15^{\circ}$ and $20^{\circ} \mathrm{N}$ before and after the monsoon onset, respectively. Both during the first rainy season in spring and the monsoon season in summer, the nocturnal jet brings moisture in the boundary layer north of the ITCZ favoring humidification and initiation of new convective cells, helping the northward progression of the ITCZ. At the end of the summer the southward return of the ITCZ is associated with the disappearance of the core of the monsoon jet.

Despite a lot of similarities between the results obtained using NCEP-DOE and ERA-40 reanalyses, giving confidence in the significance of these results, some differences are identified, especially in the diurnal cycle of deep convection, which limit the interpretation of some of these results and highlight discrepancies in the reanalyses.
\end{abstract}

\section{Introduction}

West African societies are highly vulnerable to the monsoon rainfall variability, especially in the Sahel where rain-fed crop production is the main source of food and income of one of the world's most rapidly

Corresponding author address: Dr. Benjamin Sultan, LOCEAN/IPSL, UPMC, Boite 100, T45/55, 4 Place Jussieu, 75252 Paris CEDEX 05, France.

E-mail: benjamin.sultan@locean-ipsl.upmc.fr growing populations (Baron et al. 2005). Thus, the understanding of the West African monsoon (WAM) has become a key scientific issue to improve the monsoon forecasting and respond to West Africa's food crisis. Rainfall over West Africa is linked to the meridional migration of the intertropical convergence zone (ITCZ). Following the migration of the sun the monsoon develops during the northern spring and summer, bringing the ITCZ and the associated rainfall maxima to their northern location in August (Hastenrath 1995).

WAM has been widely studied from large scales such

DOI: $10.1175 / J C L I 4218.1$

(C) 2007 American Meteorological Society 
as interannual and decadal variability including the long-term drought over the Sahel (Lamb 1978a,b; Folland et al. 1986; Rowell et al. 1995; Ward 1998; Rowell 2001; Janicot et al. 2001) to finer scales such as synoptic easterly waves (Reed et al. 1977; Duvel 1990; Diedhiou et al. 1999) and mesoscale convective systems (MCSs; Laing and Fritsch 1993, 1997; Hodges and Thorncroft 1997; Mathon and Laurent 2001). However, most of these studies introduce a strong dependence between both time and space scales. A lot of processes, in particular the interactions between large-scale dynamics and land surface controlling the diabatic processes at fine scales are still not well observed, described, or understood. This leads to recurrent problems in simulating the WAM rainfall in weather or climate models (see, e.g., Lebel et al. 2000; Yang and Slingo 2001) as the WAM dynamics variability is strongly linked to MCS occurrence and life cycle (D'Amato and Lebel 1998; Le Barbé et al. 2002). Although the diurnal cycle of deep convection in the ITCZ and MCS has been widely studied, showing an enhancement in late afternoon and a peak in the evening (Yang and Slingo 2001; Mohr 2004), very few studies have documented the diurnal cycle of the basic features of the WAM, such as the monsoon flow and the Saharan-heat low (SHL), and how the different processes interact at this time scale. Using atmospheric analyses and surface data, Parker et al. (2005) have shown a significant diurnal variability of the West African low-level monsoon winds, which get stronger overnight (the so-called nocturnal jet) once the sensible heating at the surface decreases. Also recently, Peyrille and Lafore (2007) used an idealized two-dimensional model to highlight one possible mechanism explaining the interaction between the deep convection in the ITCZ and the SHL region at the diurnal time scale. They show that weak convection in upper levels in the SHL region may be initiated by gravity waves generated by convective bursts in the ITCZ.

The objective of this study is to document and analyze the diurnal cycle of the main features of the WAM on a seasonal time scale with particular attention focused on the monsoon onset period, which has not yet been investigated in the above-mentioned studies. Sultan and Janicot (2003) showed that the onset of the monsoon is linked to an abrupt shift of the ITCZ from a quasi-stationary location at $5^{\circ} \mathrm{N}$ in May-June to another stationary location at $10^{\circ} \mathrm{N}$ in July-August. It corresponds to major changes in the atmospheric dynamics. During the two months preceding the onset stage, the SHL dynamics controls the circulation in the low and midlevels with the highest intensity of its meridional circulation at the time of the monsoon onset. It leads to an increase of convective inhibition through intrusion of dry and subsiding northerly air and an enhancement of potential instability through a greater inland moisture advection and a higher monsoon depth. In addition, the convective inhibition is enhanced along the coastline due to the ocean cooling at the end of June. The deepening of the SHL at the time of the monsoon onset can be due partly to an interaction with northern African orography (Drobinski et al. 2005). Afterward the accumulated potential instability breaks the convective inhibition and the northern Hadley-type circulation develops fully as deep convection in the ITCZ intensifies and propagates northward. Similarly to Sultan and Janicot (2003) approach, we will use a composite analysis of the National Centers for Environmental Prediction-Department of Energy (NCEPDOE) reanalysis and the 40-yr European Centre for Medium-Range Weather Forecasts Re-Analysis (ERA40) to document the diurnal cycle of the WAM, its seasonal modulation, and its variability before and after the monsoon onset. The use of the two reanalysis datasets is an important concern of this study. At this time scale, very few data are available for the assimilation processes used to produce the two reanalyses and the diurnal cycle is thus strongly dependant on the numerical model used for operational weather forecasting. Several intercomparison studies (see, e.g., Sterl 2004) have shown that the two reanalyses differ the most where less instrumental data are available and, as very few validation data are available, one needs to be careful in the description of the diurnal cycle of the WAM, which could be reanalysis dependent. We thus apply the same methodology to each reanalysis dataset and comment on their similarities and discrepancies at each step of the analysis.

Section 2 introduces the datasets and the methodology used to describe the dominant spatial and seasonal patterns of the diurnal cycle of the WAM. Sections 3 and 4 present and discuss these patterns in the lower and upper levels, respectively. Section 5 concludes the study.

\section{Dataset and methodology}

\section{a. The NCEP-DOE and ERA-40 reanalyses}

NCEP and the National Center for Atmospheric Research (NCAR) have completed a reanalysis project with a current version of the Medium-Range Forecast (MRF) model (Kalnay et al. 1996). This dataset consists of a reanalysis of the global observational network of meteorological variables (wind, temperature, geopotential height, humidity on pressure levels, surface variables, and flux variables like precipitation rate) with a 
"frozen" state-of-the-art analysis and forecast system with T62 triangular spectral truncation to perform data assimilation from 1948 to the present. This enables researchers to circumvent problems of previous numerical weather prediction analyses due to changes in techniques, models, and data assimilation. Data are reported on a $2.5^{\circ} \times 2.5^{\circ}$ grid every $6 \mathrm{~h}(0000,0600,1200$, and 1800 UTC), on 17 pressure levels from 1000 to 10 $\mathrm{hPa}$, which are good resolutions for studying synoptic weather systems. This study uses the NCEP-DOE the Atmospheric Model Intercomparison Project (AMIP-II) Reanalysis (Reanalysis-2) based on the NCEP-NCAR reanalysis but with improvements of the physical parameterizations and error fixes (Kanamitsu et al. 2002). Here we use the data covering the 1979-2000 period with four values per day.

ECMWF has released reanalyzed datasets for the time frame 1957-2002 (Simmons and Gibson 2000). The ERA-40 has a finer resolution corresponding to a T159 spectral truncation with 60 vertical levels from 1000 to $0.1 \mathrm{hPa}$. Data are reported on a $1.125^{\circ} \times 1.125^{\circ}$ grid every $6 \mathrm{~h}(0000,0600,1200$, and 1800 UTC). In this study, we use the data covering the 1979-2000 period with four values per day.

These two sets of reanalyses are processed in a similar way as Sultan and Janicot (2003). The authors applied a quasi-objective method to define a date $t_{0}$ of the monsoon onset by using daily gridded rainfall data over the period 1968-90 and then used these dates to compute a composite mean of atmospheric patterns by using the monsoon onset date for each year as the respective reference date. We have also used a similar method but applied it to outgoing longwave radiation (OLR) data (Liebmann and Smith 1996) in order to define $t_{0}$ for each year from 1979 to 2000. In tropical areas, deep convection and rainfall at large scales can be estimated through low OLR values. We verified that the onset dates $t_{0}$ detected by using OLR data for the overlapping years 1979-90 are close to those given by Sultan and Janicot (2003) based on rainfall data. The distribution of $\mathrm{t}_{0}$ from 1968 to 2000 is characterized by a mean on 24 June and a standard deviation of 7 days. We then used these dates to define a composite mean around $t_{0}$ of each atmospheric variable over the 1979-2000 period by averaging the time sequences of all the years, taking the respective $t_{0}$ dates as the time origin. In this study, we used the composite fields on the period $t_{0}-90$ to $\mathrm{t}_{0}+140$ days obtained from the NCEP-DOE and ERA-40 reanalyses. Notice that this composite analysis does not enable us to point out small-scale structures in atmospheric fields as the composite mean over $22 \mathrm{yr}$ smoothes the details of the daily synoptic features and introduces some noise induced by the uncertainty of a few days in the detection of the WAM onset. Thus, it is not obvious that we can take any advantage of using the fine resolution of the ERA-40 reanalysis and we prefer to smooth ERA-40 to the NCEP-DOE reanalysis resolution in order to easily compare the WAM diurnal cycle of the two reanalysis datasets.

The use of the two reanalysis datasets is useful to provide a degree of uncertainty in the results while studying time scales or areas where validation and/or assimilated data are low. It is important to remember that a reanalysis is a combination of model and measurement, using observations to constrain the dynamical model to optimize it between the properties of complete coverage and accuracy (Betts et al. 2006). Even if the assimilation processes to produce the NCEP-DOE and ERA-40 are close, the two products differ in several aspects. First, the two atmospheric models are different with parameterization schemes and resolution differing between NCEP-DOE and ERA-40. Second, the assimilation of satellite data is very different in the two reanalyses (see Dell'Aquila et al. 2005). For instance, both ERA-40 and NCEP-DOE reanalyses assimilate the Television Infrared Observation Satellite (TIROS) Operational Vertical Sounder (TOVS) data but ERA-40 assimilates the satellite radiance directly while NCEP-DOE assimilates the profiles of retrieved temperature and humidity. Third, the instrumental data basis has very large spatial and temporal homogeneities. It could induce discrepancies between the two reanalysis datasets depending on the scale and on the studied area taking into account the intercomparison studies. For instance, although Sterl (2004) could not find any significant difference between the two reanalysis datasets in the Northern Hemisphere using the monthly averages, Dell'Aquila et al. (2005) reported several discrepancies by using the daily time scale. Sterl (2004) also noticed than the two reanalyses differ the most where less observational data are available.

\section{b. Data processing}

In this study, we perform extended empirical orthogonal function (EEOF) analysis as well as wavelet analysis on NCEP-DOE and ERA-40 reanalyses (Kutzbach 1967; Weare and Nasstrom 1982). This method takes advantage of the fact that geophysical fields are often significantly correlated in both space and time. The dominant functions resulting from the EEOF analysis are thus interpretable not only in terms of the dominant modes of variability (as in the EOF analysis) but also in terms of the dominant modes of space-time sequences of events (Weare and Nasstrom 1982). This analysis is particularly suited for the present study as we want to describe the dominant spatial and 
seasonal patterns of the diurnal cycle using four reanalyses per day $(0000,0600,1200$, and 1800 UTC). The typical use of EEOF analysis in this study is as follows:

- Let us consider the 1979-2000 composite means of the NCEP-DOE temperature and wind (both zonal and meridional components) at $925 \mathrm{hPa}$ between $\mathrm{t}_{0}-$ 90 and $t_{0}+140$ (231 days with four values per day and per atmospheric variable). Only 475 grid points corresponding to the region between $10^{\circ} \mathrm{S}-35^{\circ} \mathrm{N}$ and $30^{\circ} \mathrm{W}-30^{\circ} \mathrm{E}$ are kept in the dataset.

- We first build a matrix $\mathbf{X}$ whose columns (the variables of the analysis) are the succession of the four daily values for each grid point and each atmospheric variable (the length is $475 \times 4 \times 3=5700$ ), and whose rows are the succession of the 231 days.

- We then derive the first two EOFs from the covariance matrix of $\mathbf{X}$. Each EOF describes a succession of four spatial patterns at $0000,0600,1200$, and 1800 UTC that characterizes a dominant space-time sequence.

- The two principal components (PCs) can thus be obtained by a linear combination of the initial variables and the two first EOFs. Each PC (a daily time series of length 231) represents the temporal evolution of the associated EOF.

On the other hand, we have used the wavelet analysis applied to NCEP-DOE and ERA-40 reanalyses to the study of the variation of the diurnal cycle amplitude of the low-levels monsoon jet along its seasonal cycle. This well-known technique is used to decompose a time series into time/frequency-space simultaneously, which is perfectly suited in the geophysical context since time series generally exhibit nonstationarity in their statistics (Farge 1992; Torrence and Compo 1998; Ouergli and De Felice 1997; Schubert et al. 1998). While the series may contain dominant periodic signals, these signals can vary in both amplitude and frequency over long periods of time.

\section{Multiscale variability of monsoon winds}

\section{a. The monsoon winds diurnal cycle and its seasonal evolution}

To describe the dominant near-surface spatial patterns of the diurnal cycle and to document their seasonal evolution, we perform the EEOF analysis on the wind (both zonal and meridional components) and temperature at $925 \mathrm{hPa}$. The analysis is performed separately using NCEP-DOE and ERA-40 reanalyses in order to attest the robustness of the dominant patterns extracted by the statistical method. The ERA-40 fields were thus interpolated on the NCEP-DOE spatial grid. The first two dominant modes explain around $86.7 \%$ $(86.3 \%)$ of the variance of the diurnal cycle of the NCEP-DOE (ERA-40) wind and temperature at $925 \mathrm{hPa}$.

The seasonal evolution of the diurnal patterns from 0000 to 1800 UTC for the first leading EOF of the analysis is represented in Fig. 1. This mode explains $66.4 \%(70.5 \%)$ of the variance of the NCEP-DOE (ERA-40) wind and temperature fields at $925 \mathrm{hPa}$. As the spatial patterns are very close using ERA-40 and NCEP-DOE, we only show the NCEP-DOE EOF patterns. This mode first depicts a clear diurnal cycle in temperature over West Africa around $10^{\circ} \mathrm{N}$ with lower temperatures at 1800 UTC. This temperature minimum corresponds to the development of cloudiness associated with deep convection at the end of the afternoon at the location of the ITCZ in summer. Figure 1 shows also a temperature maximum in northern West Africa around the Atlas Mountain where temperature increases at 1200 and 1800 UTC and decreases at 0600 UTC due to the insolation difference between night and day. The dominant signal in the $925-\mathrm{hPa}$ wind is the intensification of the southwesterly winds between $15^{\circ}$ and $20^{\circ} \mathrm{N}$ at night (0000 and 0600 UTC). It corresponds to the development of the nocturnal jet previously noticed by Parker et al. (2005) from ERA-40 reanalysis and surface data of August 2000. This jet is located north of the ITCZ and south of the intertropical front (ITF). The ITF delineates the boundary between the moist southwesterly monsoon winds on the south from the dry northeasterly Harmattan winds on the north (Hastenrath 1995; Sultan and Janicot 2003). This jet has a southwesterly component and brings moisture north of the ITCZ favoring humidification of the boundary layer and initiation of new convection cells, leading to the northward progression of the ITCZ. Another interesting point is the out-of-phase evolution of the monsoon jet and the temperature over North Africa. The jet is strong at night when the temperature is low, and vice versa. This has been explained both from observations (Parker et al. 2005) and from numerical simulations (Racz and Smith 1999): when temperature is high during the day, vertical mixing is strong in the boundary layer of the SHL and brings moisture upward with weak low-level wind; at night, vertical stratification increases, vertical mixing decreases, and low-level wind accelerates. So, the nocturnal jet brings moisture northward, which is in turn mixed and transported upward during daytime, thus enabling convection initiation north of the ITCZ.

In addition, Fig. 1 also shows the time evolution between $t_{0}-90$ and $t_{0}+140$ of the spatial patterns as- 
(a) 0000 UTC

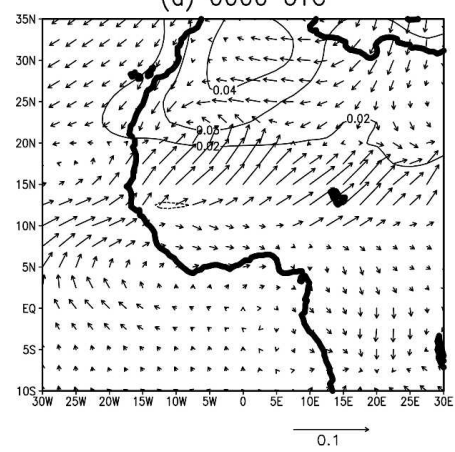

(c) 1200 UTC

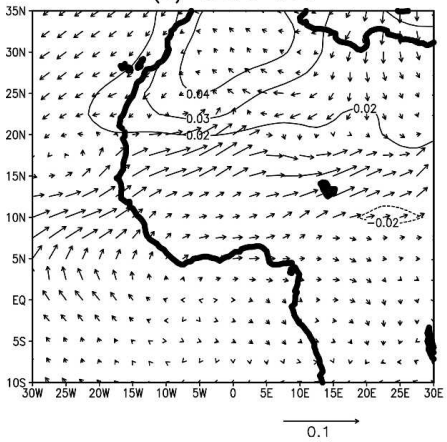

(e) 0600-1800 NCEP

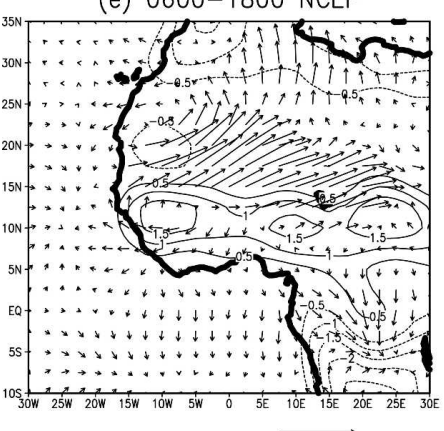

(b) 0600 UTC

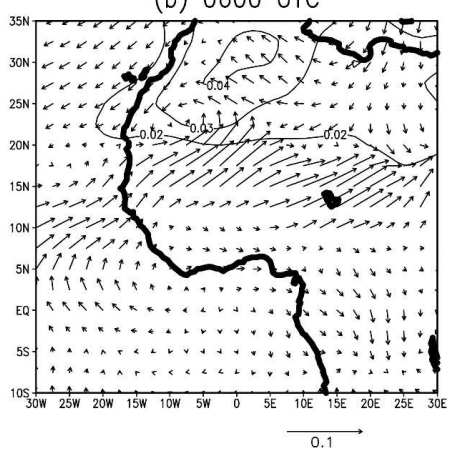

(d) 1800 UTC

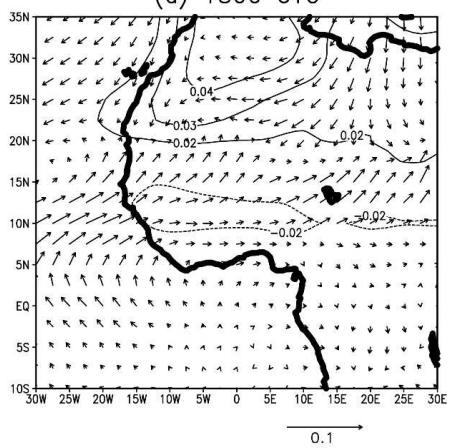

(f) 0600-1800 ERA40

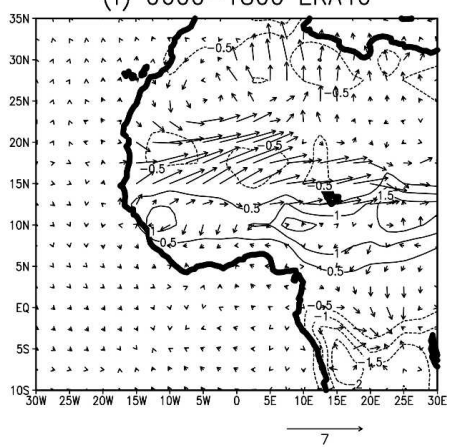

(g) PC1 NCEP \& ERA40

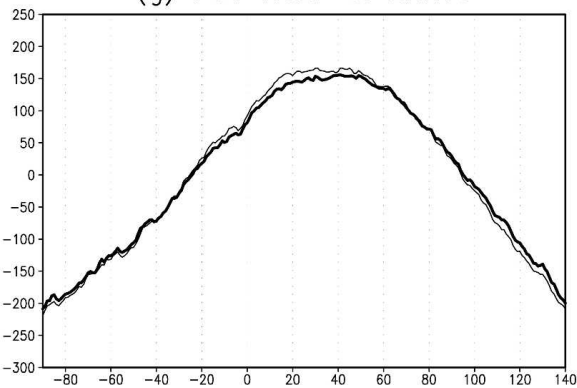

Fig. 1. First EOF at (a) 0000, (b) 0600, (c) 1200, and (d) 1800 UTC of the EEOF analysis on the NCEP-DOE wind (vectors) and temperature (contour lines) at $925 \mathrm{hPa}$. (e) NCEPDOE 925-hPa wind $\left(\mathrm{m} \mathrm{s}^{-1}\right)$ and temperature $(\mathrm{K})$ difference between 0600 and 1800 UTC reconstructed from the first EOF and averaged between $t_{0}$ and $t_{0}+60$ (the postonset period, i.e., July-August). (f) Same as in (e), but for ERA-40. (g) First PC time series from the EEOF on the NCEP-DOE (bold line) and ERA-40 (thin line) wind and temperature fields from $t_{0}-90$ to $t_{0}+140$ days, where $t_{0}$ represents the monsoon onset date. 
sociated with the first EOF, very similar in NCEPDOE and NCAR reanalyses. The time series displays a gradual increase from negative to positive values between $t_{0}-90$ and $t_{0}+20$ (mid-July), followed by a plateau between $t_{0}+20$ and $t_{0}+60$ (end of August), and a slow decrease from positive to negative values between $t_{0}+60$ and $t_{0}+90$. The diurnal sequence depicted by the first EOF is thus characterized by a seasonal evolution with a maximum between mid-July and August after the monsoon onset. The nocturnal jet is highlighted by reconstructing the $925-\mathrm{hPa}$ wind and temperature with the first EOF and by computing the difference between 0600 and 1800 UTC reconstructions averaged between $t_{0}+20$ and $t_{0}+60$. This difference is shown in Fig. 1 using both NCEP-DOE and ERA-40 reanalyses. It appears that the diurnal cycle of the monsoon winds between $15^{\circ}$ and $20^{\circ} \mathrm{N}$ is the major feature of the first leading mode and is the highest in July and August. The amplitude of this diurnal cycle and its location are very similar between NCEP-DOE and ERA-40 reanalyses.

While the first mode depicts a dominant seasonal evolution with highest values in July and August, the second EOF mode represents a second-order evolution of the seasonal cycle in term of explained variance but more closely linked to the monsoon onset (Fig. 2). This mode explains $20.3 \%(15.8 \%)$ of the variance of the NCEP-DOE (ERA-40) wind and temperature fields at $925 \mathrm{hPa}$. As for the first leading mode, the spatial patterns are very close using ERA-40 and NCEP-DOE and we only show the NCEP-DOE EOF patterns. The diurnal sequence of temperature is quite similar to that for the first leading mode (Fig. 1) with a more pronounced diurnal cycle over the continent between $10^{\circ}$ and $15^{\circ} \mathrm{N}$. At this location, the highest EOF values are observed at 1800 UTC and the lowest at 0600 UTC. As for Fig. 1, it can be highlighted by computing the difference between 0600 and 1800 UTC reconstructions with the second EOF. This difference illustrates the amplitude of the diurnal cycle of temperature at 925 $\mathrm{hPa}$ with a maximum around $12.5^{\circ} \mathrm{N}$. As for the first EOF, the main characteristic of the diurnal cycle of the wind is the diurnal evolution of southwesterly winds whose amplitude can be analyzed using the $0600-1800$ UTC difference. The nocturnal jet appears very clearly but at a more southern location in comparison with the first EOF pattern. The highest diurnal amplitude of the near-surface monsoon wind is localized between $10^{\circ}$ and $15^{\circ} \mathrm{N}$, out of phase with the temperature.

According to the PC time series (Fig. 2g), it appears that both the temperature and jet diurnal amplitudes are the highest during May and June (i.e., two months preceding the onset date $t_{0}$ ) and then gradually de- crease. May and June correspond to the first rainy season along the Guinean coast when the ITCZ remains around $5^{\circ} \mathrm{N}$. This evolution, which is visible on the temperature diurnal cycle, is due to the humidification of the surface by the northward-migrating ITCZ after the monsoon onset $t_{0}$, which reduces the diurnal thermal amplitude in the rainy areas.

It is worth noticing the differences between the time series associated with the first two EOFs. If the first PC shows a slow seasonal evolution with the highest values in July and August, the second PC shows the highest values in May and June followed by an abrupt decrease just after $t_{0}$. The EEOF analysis separates what belongs to a smooth seasonal evolution all over the year with a peak in July-August from what can be associated with the onset signal (i.e., the shift of the ITCZ from the Guinean coast to $\left.10^{\circ} \mathrm{N}\right)$. The robustness of the analysis is attested to by the very similar results obtained by using ERA-40 and NCEP-DOE reanalyses.

\section{b. The nocturnal jet}

The major feature depicted by the previous EEOF analysis at $925 \mathrm{hPa}$ is the nocturnal jet. Notice that the term "nocturnal jet" is used in reference to the work of Parker et al. (2005) to designate low-level monsoon winds showing a strong diurnal amplitude. Figure 3 represents the time-latitude evolution of the NCEP-DOE wind speed at $925 \mathrm{hPa}$ at each time step $(0000,0600$, 1200 , and 1800 UTC). The wind speed is averaged between $10^{\circ} \mathrm{W}$ and $10^{\circ} \mathrm{E}$ according to the work of Sultan and Janicot (2003). These authors have shown that the abrupt shift of the ITCZ linked to the monsoon onset occurs mostly between $10^{\circ} \mathrm{W}$ and $5^{\circ} \mathrm{E}$ where a meridional land-sea contrast exists, that is, the concept of the monsoon system as a large-scale cross-equatorial atmospheric circulation from an oceanic basin on one side and a land area on the other side is well established. Outside of this longitudinal band, the ITCZ show a rather progressive meridional excursion (Sultan and Janicot 2003). Figure 3 points out the wind speed variations between $t_{0}-90$ and $t_{0}+140$. The shaded areas highlight the wind speed values higher than $6 \mathrm{~m} \mathrm{~s}^{-1}$. The black solid line represents a null zonal wind component to delineate the domain of the monsoon winds (i.e., westerly component) and to detect the location of the ITF. Replication of Fig. 3 using ERA-40 reanalysis indicates very similar patterns so the description of this figure given above applies equally to the ERA-40 winds.

The time-latitude diagrams in Fig. 3 show a great contrast in wind speed between night (0000 and 0600 UTC) with stronger winds and day (1200 and 1800 UTC) with weaker winds (Figs. 1 and 2; see also Parker 
(a) 0000 UTC

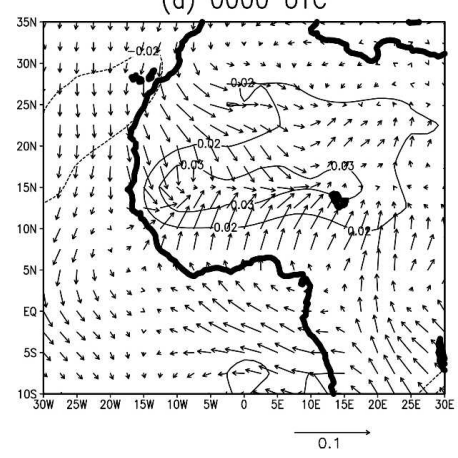

(c) 1200 UTC

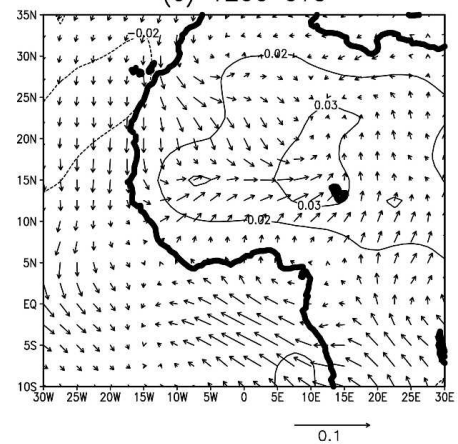

(e) $0600-1800$ NCEP

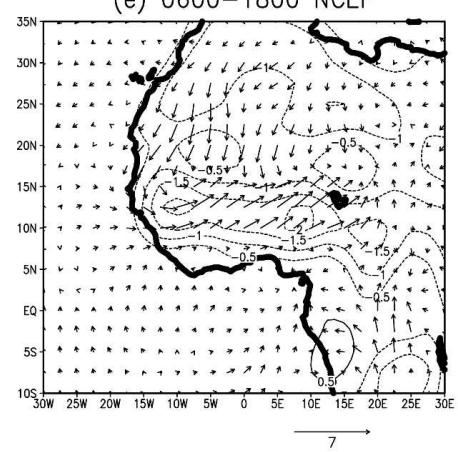

(b) 0600 UTC

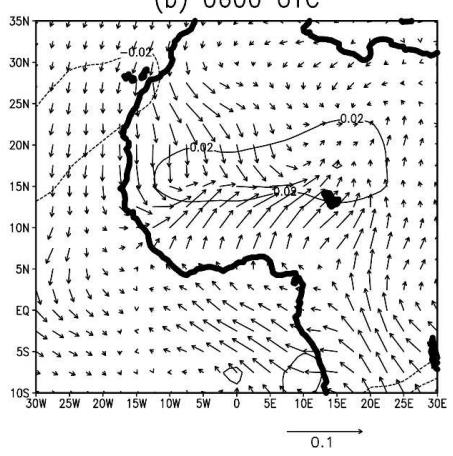

(d) 1800 UTC

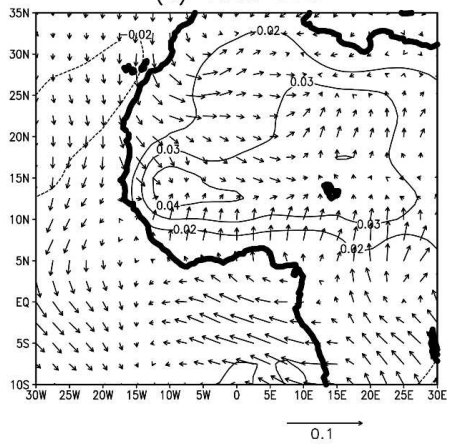

(f) $0600-1800$ ERA40

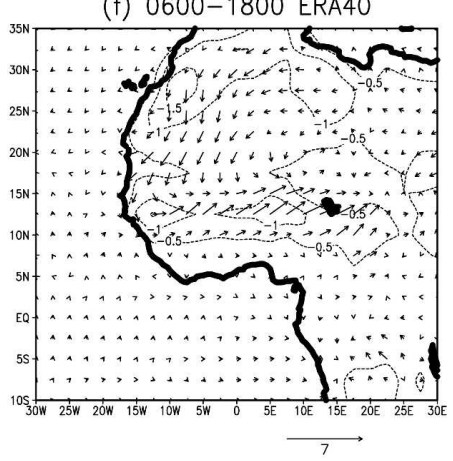

(g) PC2 NCEP \& ERA40

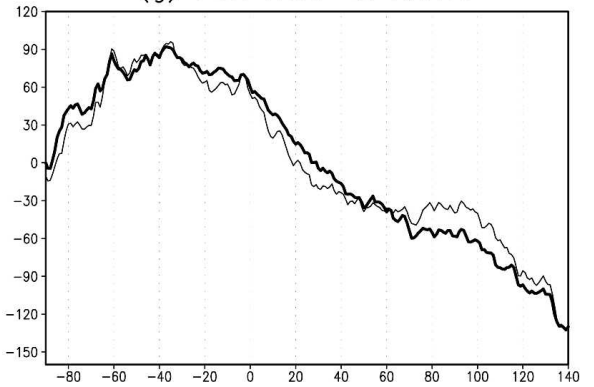

FIG. 2. Same as in Fig. 1, but for the second EOF and PC. The reconstructed fields of (e) and (f) are averaged between $t_{0}-60$ and $t_{0}$, respectively (the preonset period, i.e., May-June).

et al. 2005). The winds are the strongest at 0600 UTC both for southwesterly components south of the ITF and easterly components north of the ITF (up to 8 $\mathrm{m} \mathrm{s}^{-1}$ ). This synoptic time is in sharp contrast with
1800 UTC when the wind speed hardly reaches $4 \mathrm{~m} \mathrm{~s}^{-1}$. At 0600 UTC, the strongest southwesterly winds south of the ITF move gradually to the north between $t_{0}-90$ and $t_{0}-30$ reaching $11^{\circ} \mathrm{N}$. This northward migration 
(a) 0000 UTC

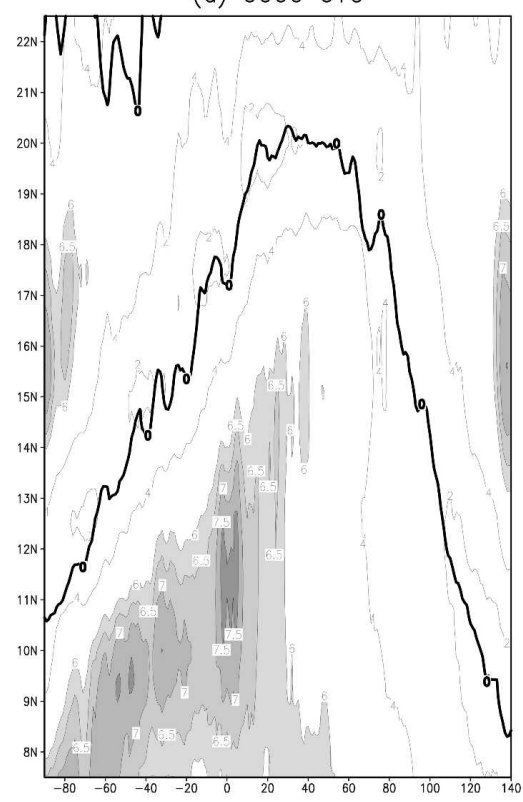

(c) 1200 UTC

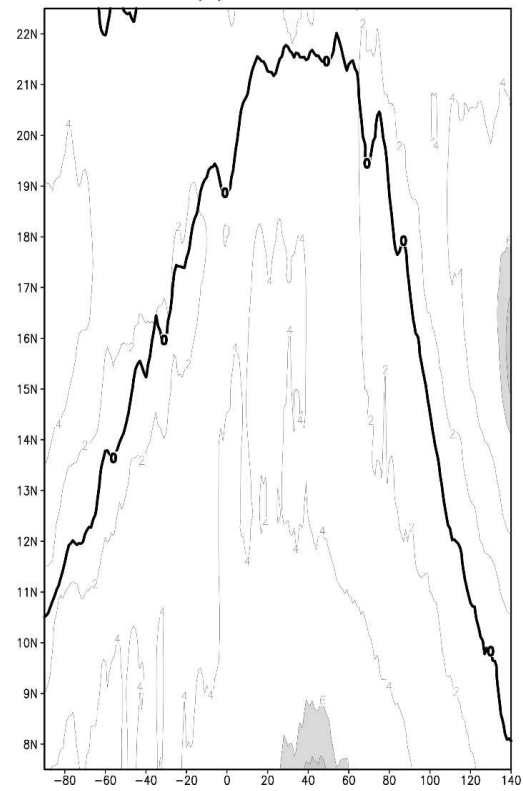

(b) 0600 UTC

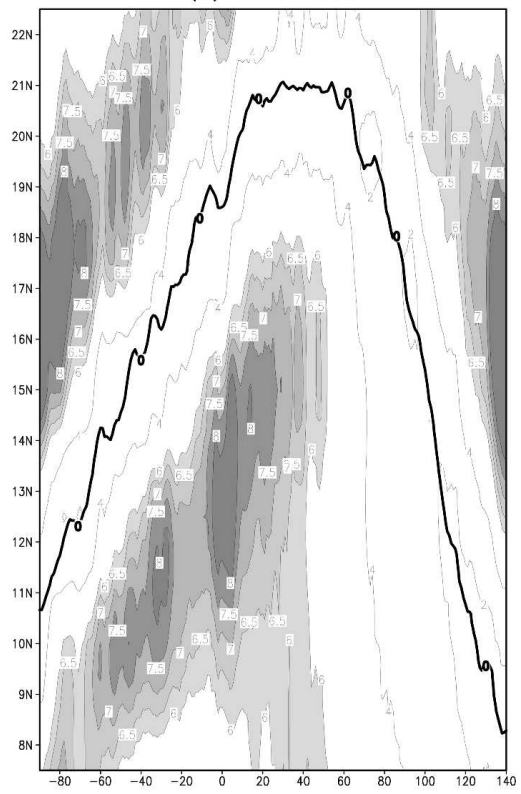

(d) 1800 UTC

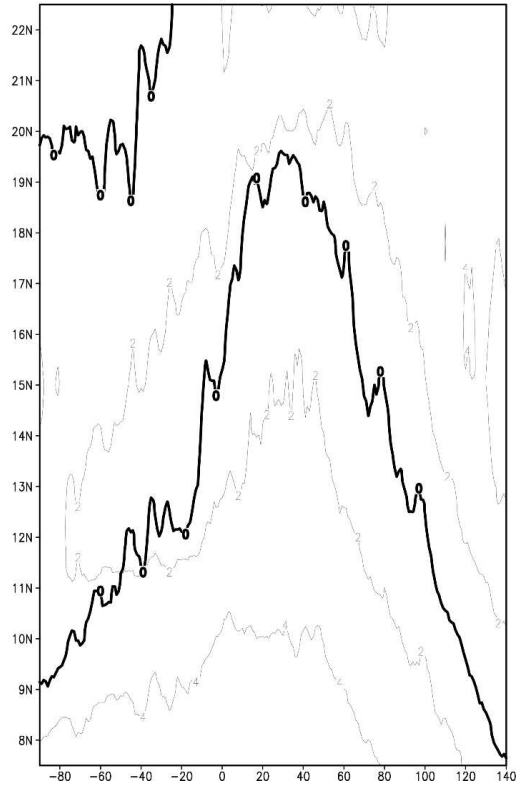

FIG. 3. Composite NCEP-DOE wind speed at $925 \mathrm{hPa}$ averaged between $10^{\circ} \mathrm{W}$ and $10^{\circ} \mathrm{E}$ $\left(\mathrm{m} \mathrm{s}^{-1}\right)$. Values greater than $6 \mathrm{~m} \mathrm{~s}^{-1}$ are shaded. The thick line represents a null zonal wind component. Wind speed values have been smoothed by using a 5-day running mean and are shown at (a) 0000, (b) 0600, (c) 1200, and (d) 1800 UTC from $t_{0}-90$ to $t_{0}+140$ days, where $t_{0}$ represents the monsoon onset date. Wind speed values have been smoothed by using a 5-day running mean filter.

slows down after a peak of wind speed up to $8 \mathrm{~m} \mathrm{~s}^{-1}$ with a quasi-stationary location of the highest winds at $12^{\circ} \mathrm{N}$ between $t_{0}-20$ and $t_{0}$. Just after the monsoon onset, the winds strengthen with a rapid northward progression reaching $15^{\circ} \mathrm{N}$ at $t_{0}+15$. They remain constant at this location until $t_{0}+50$ and weaken afterward. Strong southwesterly winds are also observed at 0000 UTC but with smaller values and located more to the south than at 0600 UTC. The ITF location also shows a strong diurnal cycle with its southernmost position at 
1800 UTC and its northernmost position at 0600 and 1200 UTC. The southernmost location is partly due to the northeasterly sea breeze that blows at about $3 \mathrm{~m} \mathrm{~s}^{-1}$ along the Mediterranean coast of Africa during daytime and penetrates inland down to $20^{\circ} \mathrm{N}$, thus preventing the northward penetration of the ITF (Fig. 1). Such a large penetration is not unusual in the tropical region (Rotunno 1983).

To document the seasonal time-latitude evolution of the amplitude of the diurnal cycle of the monsoon winds, we compute the $925-\mathrm{hPa}$ wind difference between 0600 (when the winds are the strongest) and 1800 UTC (when the winds are the weakest; Fig. 4). Again differences between the two reanalyses are small, so only NCEP-DOE fields are shown (ERA-40 fields depict similar patterns except the highest wind values are about $1 \mathrm{~m} \mathrm{~s}^{-1}$ weaker). As for Fig. 3, the ITF position is reported at 0600 (solid line) and 1800 UTC (dashed line). The amplitude of the wind diurnal cycle is maximum at the time of the monsoon onset $\left(7 \mathrm{~m} \mathrm{~s}^{-1}\right)$ around $14^{\circ} \mathrm{N}$ (Fig. 4a). Figure 4a also shows that the seasonal evolution of the wind difference is characterized by a northward migration and not a southward retreat as it is observed for rainfall or deep convection. The wind diurnal cycle tends to disappear after reaching its northern location around $16^{\circ} \mathrm{N}$. This northward migration seems to be characterized by two steps separated by the onset date $t_{0}$, each step defined by a different speed in the northward propagation (see, e.g., the $5 \mathrm{~m} \mathrm{~s}^{-1}$ isoline). Although the amplitude of the wind diurnal cycle remains the same, the northward progression appears to be slower during the premonsoon period and faster afterward.

As the two leading EOFs of the 925-hPa wind and temperature capture most part of the seasonal variability of the nocturnal jet, one can reconstruct the same 0600-1800 UTC wind speed difference by using these two EOFs. Figure 4b shows the time-latitude diagram for the reconstructed wind (the mean wind field has been added). It is very similar to Fig. 4a except it does not capture the high-frequency variability. The difference before and after $t_{0}$ is more pronounced in this reconstruction with a larger diurnal amplitude just after $\mathrm{t}_{0}$ (see the $6 \mathrm{~m} \mathrm{~s}^{-1}$ isoline). One can also document the respective contribution of each EEOF to this reconstruction (Figs. 4c,d, the mean wind field has been added). The first EOF (Fig. 4c) explains the northward migration of the nocturnal jet between $t_{0}-20$ and $t_{0}+$ 20 with maximum diurnal amplitude $\left(6 \mathrm{~m} \mathrm{~s}^{-1}\right)$ around $15^{\circ} \mathrm{N}$ between $t_{0}+20$ and $t_{0}+60$. The second EOF (Fig. 4d) explains the large diurnal cycle before $t_{0}(5$ $\mathrm{m} \mathrm{s}^{-1}$ ) around $12^{\circ} \mathrm{N}$. At this location, the diurnal amplitude increases without any northward migration be- tween $t_{0}-90$ days and $t_{0}$. It is the combination of these two effects-1) increase of the wind diurnal amplitude at $12^{\circ} \mathrm{N}$ during the premonsoon season followed by a sudden decrease after $t_{0}$ and 2) a slow northward propagation (between $12^{\circ}$ and $15^{\circ} \mathrm{N}$ ) and increase of the wind diurnal amplitude between July and August-that explains the seasonal variability of the nocturnal jet. So both during the first rainy season in spring and the monsoon season in summer, the nocturnal jet brings moisture in the boundary layer north of the ITCZ favoring humidification and initiation of new convective cells, helping the northward progression of the ITCZ. This is also consistent with the fact that at the end of the summer the southward return of the ITCZ is associated with the disappearance of the core of the monsoon jet.

The amplitude of the diurnal cycle of the low-level monsoon winds and its seasonal evolution can also be analyzed by applying a wavelet transform on NCEPDOE and ERA-40 wind speed. An average monsoon wind speed has been first computed by averaging the 925-hPa wind speed over the region extending from $7.5^{\circ}$ to $20^{\circ} \mathrm{N}$ and from $10^{\circ} \mathrm{W}$ to $10^{\circ} \mathrm{E}$. This domain has been chosen in order to capture the nocturnal jet two months before and after $t_{0}$. We only include the westerly winds so wind speed north of the ITF in the $7.5^{\circ}-$ $20^{\circ} \mathrm{N}$ latitude band is removed from the averaging procedure. The time series of the 6-hourly and daily average monsoon wind in NCEP-DOE and ERA-40 reanalysis datasets are shown in Figs. 5a,c. The NCEPDOE daily mean (Fig. 5a) depicts a very low variability with a near constant value of $5 \mathrm{~m} \mathrm{~s}^{-1}$ before $t_{0}+40$ followed by a gradual decrease down to $1 \mathrm{~m} \mathrm{~s}^{-1}$ at $t_{0}+$ 140. This time series is slightly different when using the ERA-40 wind fields (Fig. 5c). The wind speed is quasistationary around $4 \mathrm{~m} \mathrm{~s}^{-1}$ between $t_{0}-90$ and $t_{0}-20$ and shows an increase up to $5 \mathrm{~m} \mathrm{~s}^{-1}$ between $t_{0}-20$ and the onset date. After the monsoon onset the ERA40 monsoon wind index becomes closer to the NCEPDOE time series with low wind speed variability near a constant value of $5 \mathrm{~m} \mathrm{~s}^{-1}$ before $t_{0}+40$ and a gradual decrease down to $1 \mathrm{~m} \mathrm{~s}^{-1}$ at $t_{0}+140$. One can notice that the diurnal amplitude of the average NCEP-DOE and ERA-40 monsoon wind decreases with time. This modulation of the diurnal amplitude can be quantified by computing a wavelet analysis of the average monsoon wind. Figures 5b,d represent the wavelet coefficient modulus corresponding to the diurnal harmonic. The two curves based on NCEP-DOE and ERA-40 wind fields are very close. The values of the wavelet coefficient modulus are the highest before the monsoon onset and then rapidly decrease. This temporal evolution is similar to that of the second EOF (Fig. 4d) show- 
(a) $0600-1800$

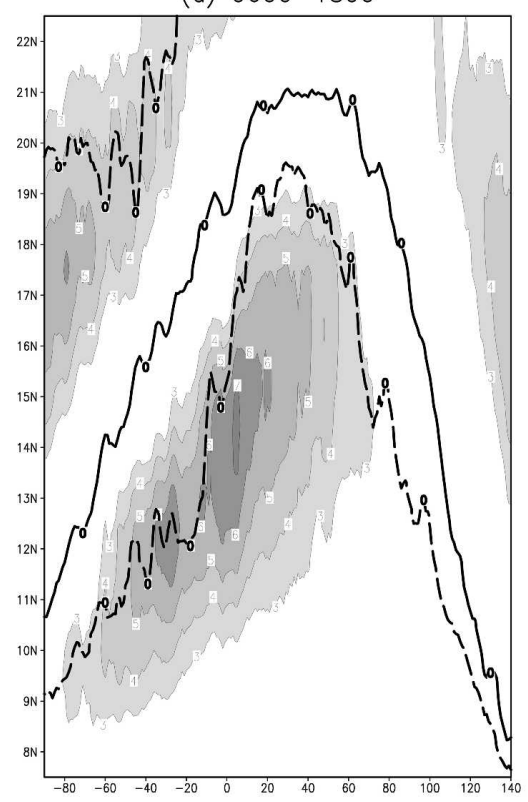

(c) $0600-1800$ EOF1

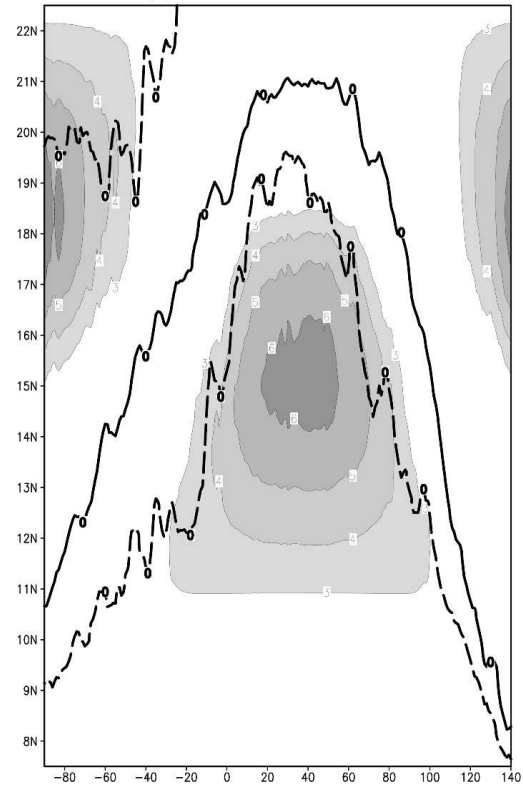

(b) 0600-1800 EOF1+EOF2

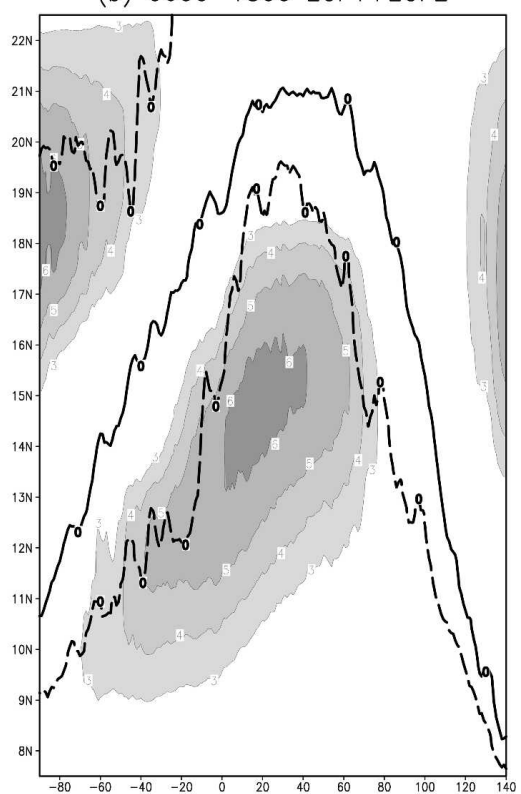

(d) 0600-1800 EOF2

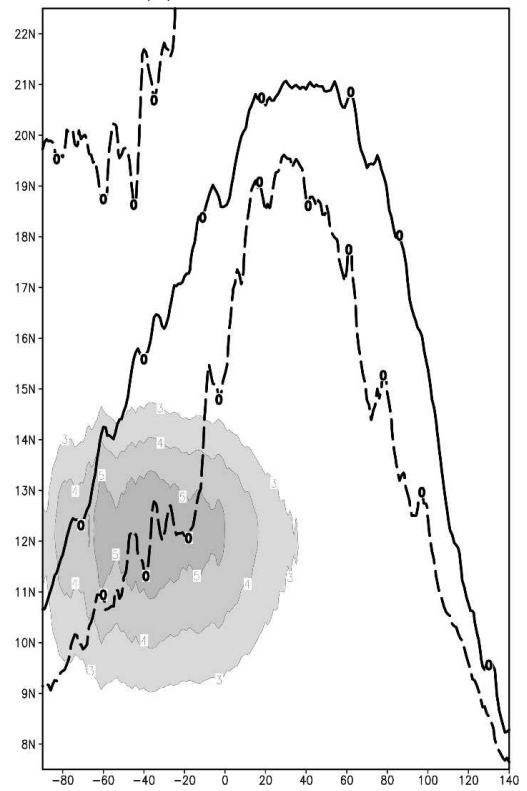

FIG. 4. (a) Composite NCEP-DOE wind speed difference at $925 \mathrm{hPa}$ between 0600 and 1800 UTC $\left(\mathrm{m} \mathrm{s}^{-1}\right)$. Only values greater than $3 \mathrm{~m} \mathrm{~s}^{-1}$ are shown. Wind speed values have been smoothed by using a 5-day running mean filter. The two thick lines represent a null zonal wind component at 0600 (solid line) and 1800 UTC (dashed line). (b) Same as in (a), but for the wind reconstruction using the first two modes of the EEOF on the NCEP-DOE wind and temperature at $925 \mathrm{hPa}$. The mean wind field has been added. (c) Same as in (b), but only using the first EOF. (e) Same as in (b), but only using the second EOF.

ing high values between $t_{0}-60$ and $t_{0}-20$ due to the nocturnal jet intensification around $12^{\circ}-13^{\circ} \mathrm{N}$ and lower values afterward. This is approximately the time when rainfall increases at these latitudes after the ITF northward propagation. This result is consistent with Parker et al. (2005) who show that the diurnal amplitude of the surface wind data is larger (smaller) during the dry (wet) season. 
(a) Average monsoon wind NCEP

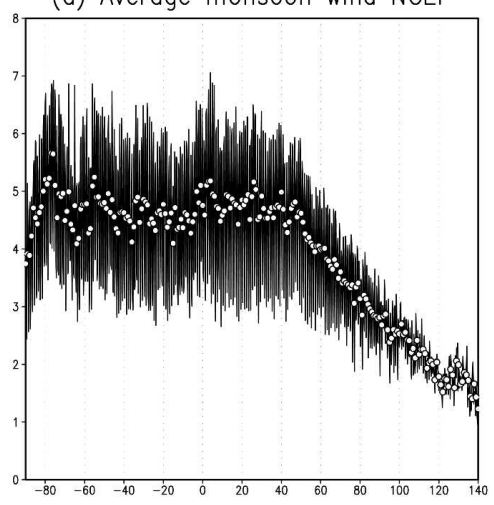

(b) 1-day wavelet modulus NCEP

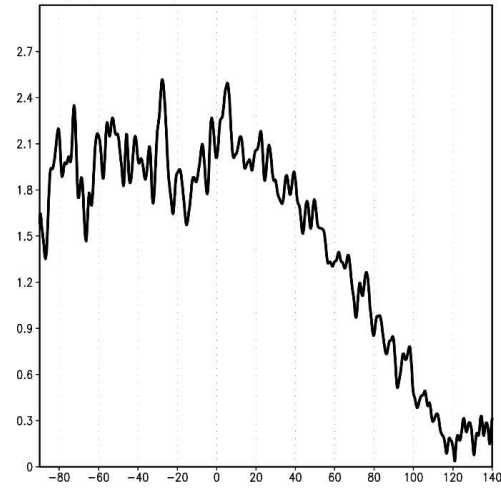

(c) Average monsoon wind ERA40

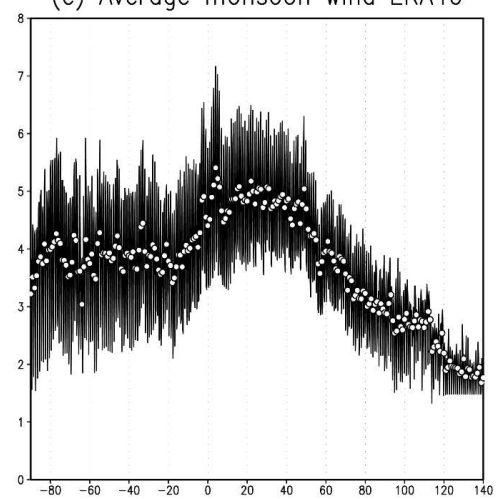

(d) 1-day wavelet modulus ERA40

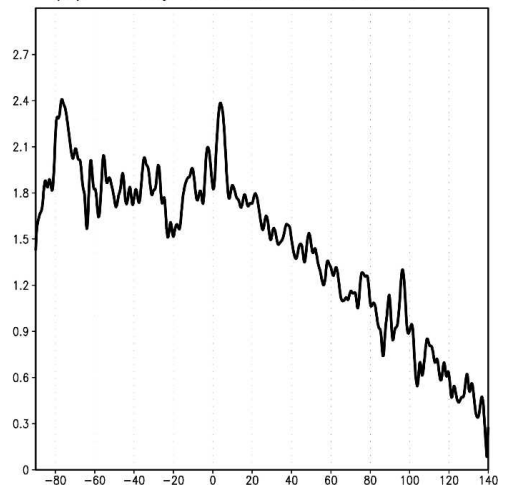

FIG. 5. (a) Composite NCEP-DOE wind speed averaged over $7.5^{\circ}-20^{\circ} \mathrm{N}$ and $10^{\circ} \mathrm{W}-10^{\circ} \mathrm{E}$ $\left(\mathrm{m} \mathrm{s}^{-1}\right)$. Only values from westerly winds are included in the averaging procedure. The time series of both the 6-hourly (black line) and daily (circle) average monsoon wind are shown from $t_{0}-90$ to $t_{0}+140$ days, where $t_{0}$ represents the monsoon onset date. (b) Wavelet modulus $\left(\mathrm{m} \mathrm{s}^{-1}\right)$ for the 1-day period. (c) Same as in (a), but using the ERA-40 reanalysis dataset. (d) Same as in (b), but using the ERA-40 reanalysis dataset.

\section{The vertical structure of the diurnal cycle and its seasonal evolution}

\section{a. Seasonal and diurnal variations in the meridional circulation}

To describe the dominant spatial patterns of the diurnal cycle in the meridional circulation and to document their seasonal evolution, we perform an EEOF analysis on the vertical and meridional wind components and temperature. The data are first averaged between $10^{\circ} \mathrm{W}$ and $10^{\circ} \mathrm{E}$ and the analysis is performed by using data from $10^{\circ} \mathrm{S}$ to $35^{\circ} \mathrm{N}$ and from 1000 to $100 \mathrm{hPa}$.

The diurnal evolution of the first leading EOF of the analysis from 0000 to 1800 UTC is represented in Fig. 6. This mode explains $70.5 \%(74.0 \%)$ of the variance of the NCEP-DOE (ERA-40) wind and temperature fields in the considered cross section. We will first describe the NCEP-DOE EOF patterns and then discuss the results obtained with ERA-40 reanalysis.
The first dominant mode highlights the diurnal cycle of the Hadley-type circulation. This circulation is the clearest at 1800 UTC with two areas of upward vertical motions, at $10^{\circ} \mathrm{N}$ between 700 and $250 \mathrm{hPa}$ and from the surface up to $600 \mathrm{hPa}$ at $20^{\circ} \mathrm{N}$ in the SHL, and a subsiding branch at $5^{\circ} \mathrm{S}$. These two areas can be associated respectively with deep convection and dry convection. At 1800 UTC, the upward vertical motions in the deep convection are associated with minimum lowlevel temperature due to rainfall-induced cooling. However, a temperature maximum is visible around $30^{\circ} \mathrm{N}$ due to the daytime radiative heating (see also Fig. 1). The Hadley-type circulation almost disappears at 0600 UTC because of the absence of deep convection whereas in the same time upward vertical motions enhance in the SHL. The diurnal cycle of the Hadley-type circulation can be analyzed by computing the difference between the 1800 and 0600 UTC reconstructions averaged between $t_{0}$ and $t_{0}+60$ (Fig. 6e). This difference is 
(a) 0000 UTC

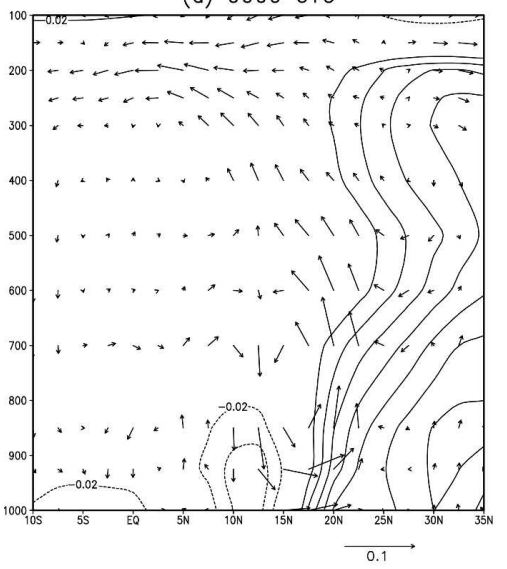

(c) 1200 UTC

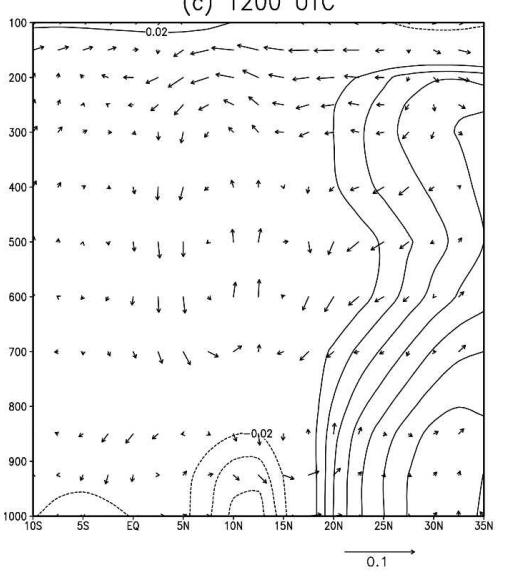

(e) $1800-0600$

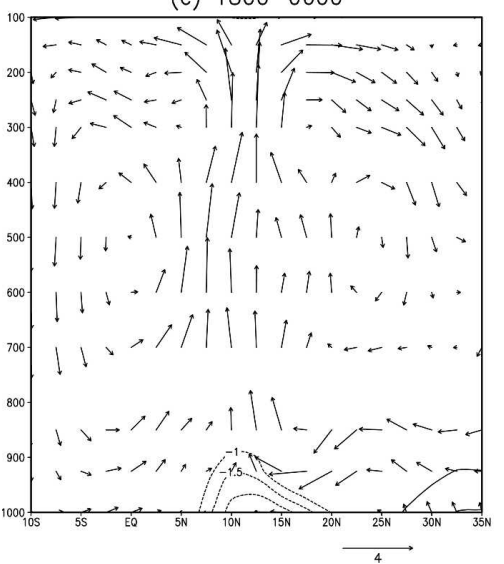

(b) 0600 UTC

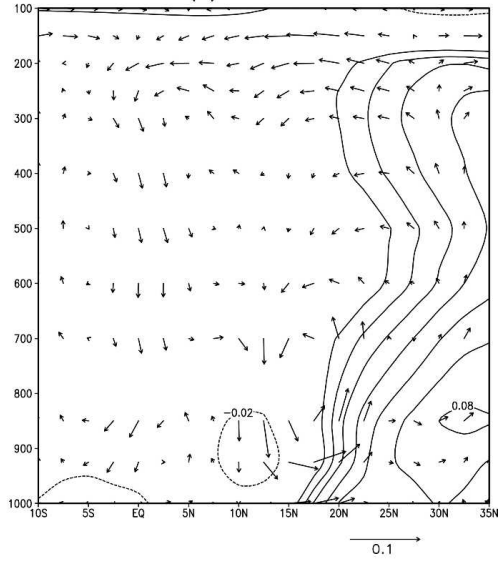

(d) 1800 UTC

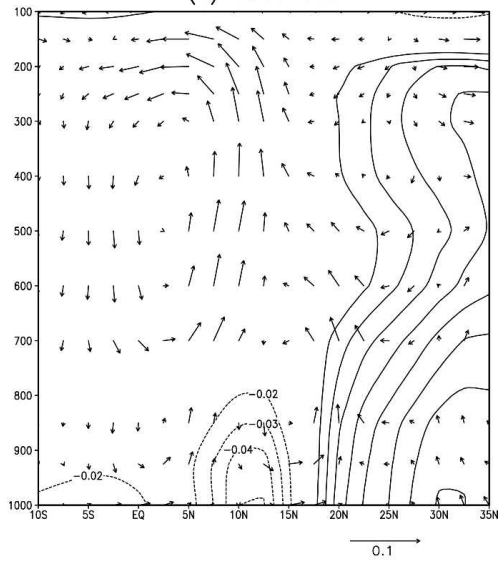

(f) PC1 NCEP \& ERA40

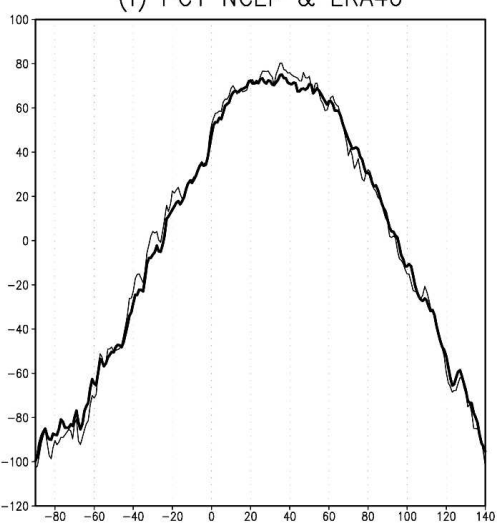

FIG. 6. First EOF at (a) 0000, (b) 0600, (c) 1200, and (d) 1800 UTC of the EEOF analysis on the NCEP-DOE latitude-pressure cross section of the $10^{\circ} \mathrm{W}-10^{\circ} \mathrm{E}$ averaged wind (vectors) and temperature (contour lines). (e) $10^{\circ} \mathrm{W}-10^{\circ} \mathrm{E}$ averaged meridional circulation difference between 1800 and 0600 UTC reconstructed from the first EOF and averaged between $t_{0}$ and $t_{0}+60$ (the postonset period, i.e., July-August). (f) First PC time series from the EEOF on the NCEP-DOE (bold line) and ERA-40 (thin line) wind and temperature fields from $t_{0}-90$ to $t_{0}+140$ days, where $t_{0}$ represents the monsoon onset date. 
very close to the schematic view of the Hadley circulation with an ascending branch localizing the deep convection at $10^{\circ} \mathrm{N}$ surrounded by two subsiding branches at $5^{\circ} \mathrm{S}$ and $30^{\circ} \mathrm{N}$. The time series of the first leading mode is very similar to the one shown in Fig. 1, showing evidence of the seasonal variability mode of the Hadley-type circulation and its diurnal cycle (Fig. 6f).

At night (0000 and 0600 UTC), when upward motions in the deep convection are very weak, the nocturnal jet is maximum between $15^{\circ}$ and $20^{\circ} \mathrm{N}$ (see also Fig. 1). The nocturnal jet is imbedded within the SHL circulation featured by a subsiding branch around $12.5^{\circ} \mathrm{N}$ between 700 and $925 \mathrm{hPa}$, dry convection up to $600 \mathrm{hPa}$ at $20^{\circ} \mathrm{N}$, and a return flow near $700 \mathrm{hPa}$ above the nocturnal jet. This circulation is most distinct at 0000 UTC, out of phase with deep convection and Hadleytype circulation, which are maximum during the daytime (Parker et al. 2005).

Although the PC time series are very similar using NCEP-DOE and ERA-40 reanalyses, the spatial patterns are quite different. The diurnal cycle of the SHL circulation (including the nocturnal jet) is the same in the two reanalyses with an amplification overnight, but the diurnal cycle of deep convection and Hadley-type circulation is much weaker in ERA-40 reanalysis (not shown). Strong upward motions associated with deep convection can be seen at every time step $(0000,0600$, 1200 , and 1800 UTC) with a small decrease at 1800 UTC contrary to the results obtained with NCEP-DOE reanalysis (see the discussion in section $4 \mathrm{~b}$ ).

The diurnal evolution of the second leading EOF of the analysis between 0000 and 1800 UTC is represented in Fig. 7. This mode explains $14.9 \%(11.5 \%)$ of the variance of the NCEP-DOE (ERA-40) wind and temperature fields in the considered cross section. We will first describe the NCEP-DOE EOF patterns and then discuss the results obtained by using ERA-40 reanalysis.

The main feature of this mode is the SHL circulation and its diurnal amplitude, which is maximum overnight (0000 and 0600 UTC). This SHL circulation is characterized by a low-level wind convergence and dry convection at $15^{\circ} \mathrm{N}$ up to $600 \mathrm{hPa}$. The nocturnal jet is very clear between $10^{\circ}$ and $15^{\circ} \mathrm{N}$ (see also Fig. 2) associated with near-surface warming between 0600 and 1800 UTC (see also Fig. 2). The temporal evolution of this mode explains the southern position of the SHL circulation in comparison with the first leading mode (showing dry convection located around $20^{\circ} \mathrm{N}$ ). The highest positive values of the second PC are found in May and June, so the associated spatial patterns characterize the dominant variability of the diurnal cycle during these two months. The role of this mode on the diurnal cycle amplitude decreases rapidly after $t_{0}$, whereas the first mode (Fig. 6) reaches its maximum and controls most of the diurnal cycle variability in the cross section. One can notice that the PC time series of the second EOF is very close to the one shown in Fig. 2.

One striking feature of the spatial patterns of the second mode is the large ascending branch south of $5^{\circ} \mathrm{N}$ observed at 0600, 1200, and 1800 UTC between $700 \mathrm{hPa}$ and the upper levels, with a maximum at 1200 UTC. This ascending branch is associated with a subsidence from the upper levels down to $700 \mathrm{hPa}$ at $10^{\circ} \mathrm{N}$ at 1200 and 1800 UTC with a maximum at 1800 UTC. This pattern and the associated PC depict the northward shift of the deep convection from $5^{\circ} \mathrm{N}$ in May-June (when the $\mathrm{PC}$ is positive) to $10^{\circ} \mathrm{N}$ in July-August (when the PC is negative). As the highest positive values of the second PC are found during the two months preceding $t_{0}$, the EOF indicates that deep convection is active at $5^{\circ} \mathrm{N}$ at 1200 and 1800 UTC in May-June. After the monsoon onset, as the PC decreases with negative values after $\mathrm{t}_{0}+20$, the EOF depicts a weakening of convection south of $5^{\circ} \mathrm{N}$ and convection enhancement at $10^{\circ} \mathrm{N}$. One can notice the time lag between the maximum of the upward anomaly at $5^{\circ} \mathrm{N}$ and 1200 UTC and the maximum of the downward anomaly at $10^{\circ} \mathrm{N}$ and 1800 UTC. This time lag may be due to different diurnal cycle of deep convection between the preonset months with the highest deep convection around $5^{\circ} \mathrm{N}$ at 1200 UTC and the postonset months with the highest deep convection around $10^{\circ} \mathrm{N}$ at 1800 UTC.

As for the first dominant mode, although the PC time series are very close using NCEP-DOE and ERA-40 reanalyses, the spatial patterns are quite different. The main difference is a persistent deep convection at $5^{\circ} \mathrm{N}$ in the second EOF during night and day using ERA-40 (see the discussion in section 4b). However, both datasets show a similar diurnal cycle of the SHL circulation.

\section{b. Seasonal and diurnal variations in the ITCZ and in the $H L$}

To investigate the contribution of each dominant mode previously described in the diurnal cycle of deep convection before and after $t_{0}$, we have reconstructed the vertical wind velocity at $400 \mathrm{hPa}$ (where deep convection is the most pronounced) by using the two EOFs computed from the EEOF analysis of NCEP-DOE latitude-pressure cross section of the $10^{\circ} \mathrm{W}-10^{\circ} \mathrm{E}$ averaged meridional circulation between $t_{0}-90$ and $t_{0}+140$. Figure 8 shows these reconstructions averaged over May and June (the preonset period; see Figs. 8a,c) and over July and August (the postonset period; see Figs. $8 \mathrm{~b}, \mathrm{~d})$. The mean vertical wind field is not included in order to only document the forcing imposed by each 
(a) 0000 UTC

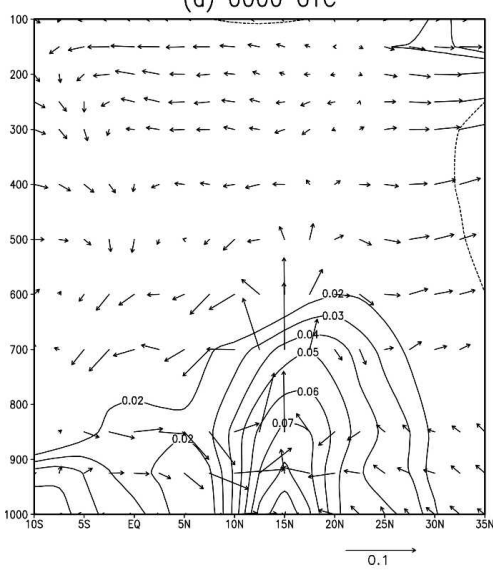

(c) 1200 UTC

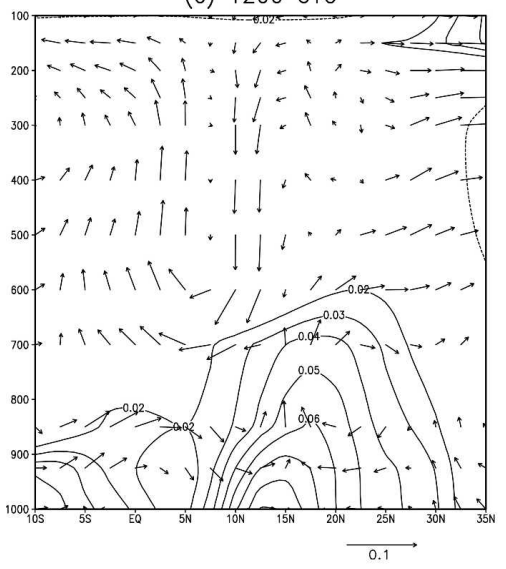

(e) $1800-0600$

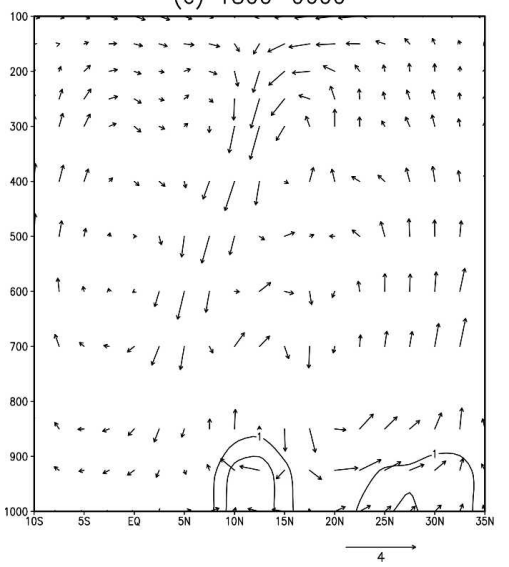

(b) 0600 UTC

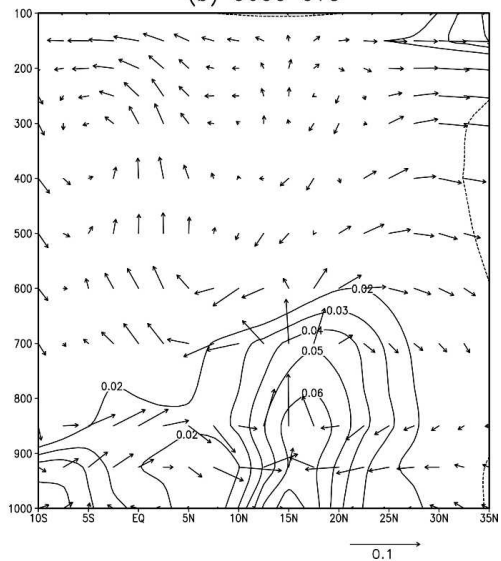

(d) 1800 UTC

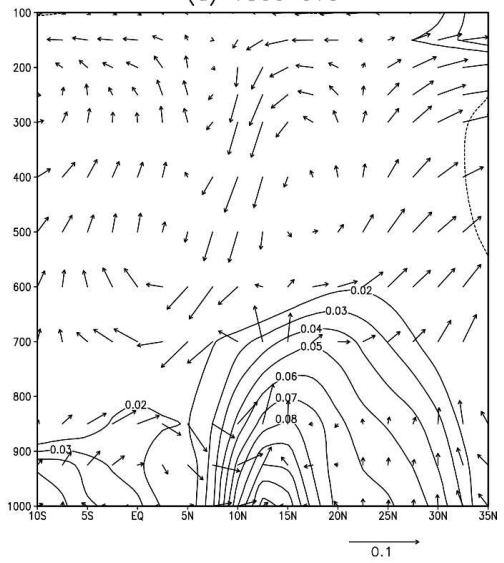

(f) PC2 NCEP \& ERA40

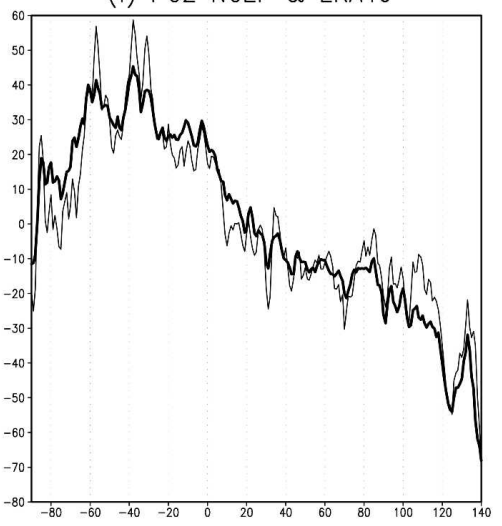

FIG. 7. Same as in Fig. 6, but for the second EOF and PC. The reconstructed fields of (e) are averaged between $t_{0}-60$ and $t_{0}$ (the preonset period, i.e., May-June).

EOF on the mean wind field. The latter is shown in Fig. 8 using NCEP-DOE (Figs. 8e,f) and ERA-40 (Figs. $8 \mathrm{~g}, \mathrm{~h}$ ) reanalyses. Negative (positive) values depict upward (downward) wind.

As discussed in the previous sections, Fig. 8 confirms that the influence of the first mode on the vertical wind is dominant during the postonset period (Fig. 8b) while it is very weak before the monsoon onset (Fig. 8a). Conversely, the second mode dominates during the preonset period (Fig. 8c) while it is very weak before the monsoon onset (Fig. 8d).

During the postonset period, the NCEP-DOE verti- 
(a) W400 PC1 (t0-60d - - > t0)

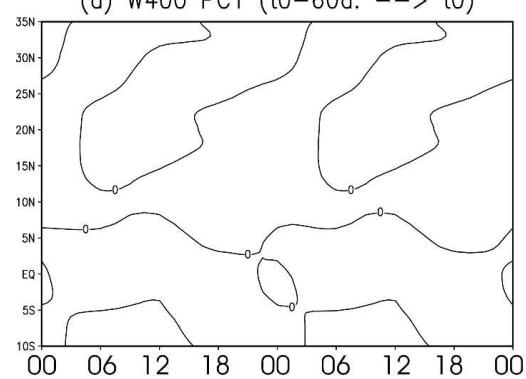

(c) W400 PC2 (t0-60d. $-\rightarrow$ to)

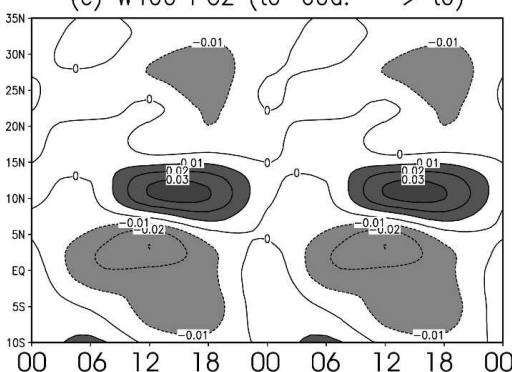

(e) W400 NCEP mean (t0-60d. $-->$ t0)

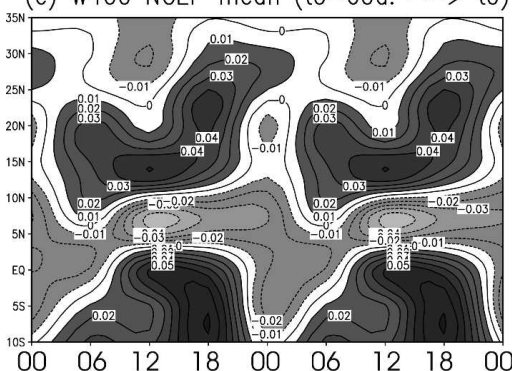

(g) W400 ERA40 mean (t0-60d. $-->$ to)

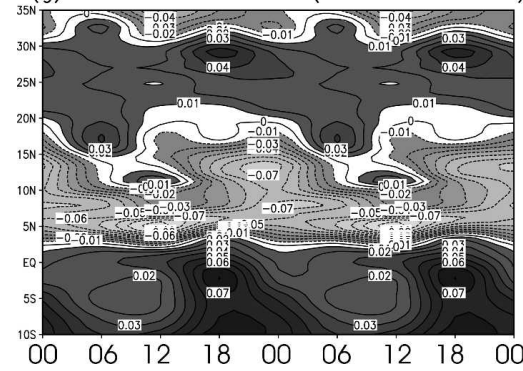

(b) W400 PC1 (to $-->$ t0+60d.)

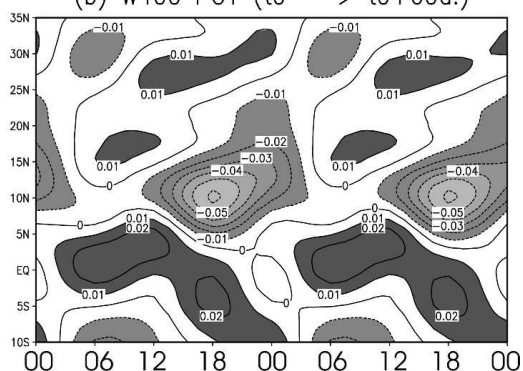

(d) W400 PC2 (t0 $-->$ to+60d.)

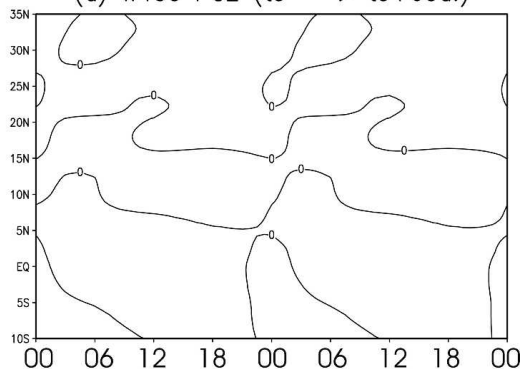

(f) W400 NCEP mean (t0 $-\rightarrow>$ t0+60d.)

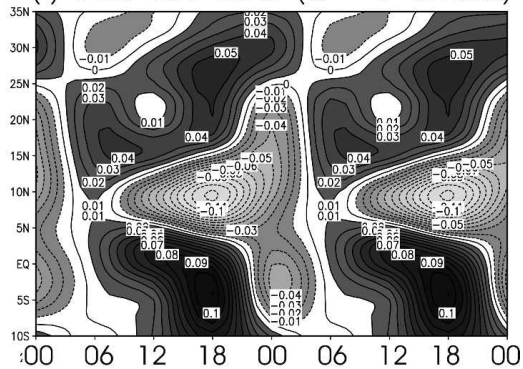

(h) W400 ERA40 mean (t0 $-->$ t0 +60 d.)

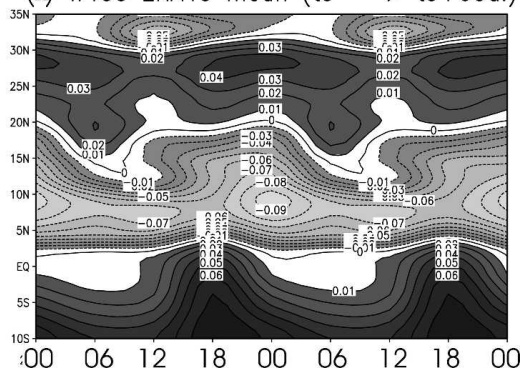

FIG. 8. (a)-(d) Reconstruction of the vertical wind velocity $\left(\mathrm{Pa} \mathrm{s}^{-1}\right)$ at $400 \mathrm{hPa}$ by using the two EOFs computed from the EEOF analysis of the NCEP-DOE latitude-pressure cross section of the $10^{\circ} \mathrm{W}-10^{\circ} \mathrm{E}$ averaged wind and temperature between $t_{0}-90$ and $t_{0}+140$. Negative (positive) values depict upward (downward) wind. The reconstructed fields of (a) and (c) are based on the first and second EOF, respectively. They are averaged between $t_{0}-$ 60 and $t_{0}$ (the preonset period, i.e., May-June). The reconstructed fields of (b) and (d) are based on the first and second EOF, respectively. They are averaged between $t_{0}$ and $t_{0}+60$ (the postonset period, i.e., July-August). The mean vertical wind field is not included in order to only document the forcing imposed by each EOF on the mean wind field. The latter is shown from (e) to (f) using NCEP-DOE reanalyses [(e) and (f) corresponding to the preonset and postonset means, respectively] and from $(\mathrm{g})$ to $(\mathrm{h})$ ERA-40 $[(\mathrm{g})$ and $(\mathrm{h})$ corresponding to the preonset and postonset means, respectively]. 
cal wind at $400 \mathrm{hPa}$ (Fig. 8f) shows a clear diurnal cycle of the Hadley-type circulation (see also Fig. 6). It is characterized by upward motions associated with deep convection at $10^{\circ} \mathrm{N}$ surrounded by two regions of subsidence near $25^{\circ} \mathrm{N}$ and near $5^{\circ} \mathrm{S}$. This Hadley-type circulation is at its maximum at 1800 UTC. The first mode (Fig. 8b) contributes mainly to explain this pattern with negative anomalies at $10^{\circ} \mathrm{N}$ at 1800 UTC and positive anomalies over the subsiding branches. The ERA-40 vertical wind velocity at $400 \mathrm{hPa}$ shows a quite different pattern (Fig. 8h). The location and the timing of the two subsiding branches $\left(5^{\circ} \mathrm{S}\right.$ and $\left.25^{\circ} \mathrm{N}\right)$ are similar to that obtained with the NCEP-DOE reanalyses, but the diurnal cycle of the vertical velocity in the deep convection area is less pronounced with convective activity during night and day. Moreover, the deep convection is the strongest at 0000 UTC and not at 1800 UTC as in the NCEP-DOE reanalyses. One can also see in the first EOF reconstruction (Fig. 8b) a propagation of negative anomalies (in the postonset period) from the deep convection location at $10^{\circ} \mathrm{N}$ and at 1800 UTC to $30^{\circ} \mathrm{N}$ near the SHL region $12 \mathrm{~h}$ later (at $0600 \mathrm{UTC}$ ). A similar propagating anomaly has been evidenced by Peyrille and Lafore (2007) who suggest that this interaction between deep convection and the upper-level circulation in the SHL region may be due to gravity wave propagation in the upper troposphere. This pattern can be seen in the NCEP-DOE vertical wind field (Fig. 8f), but not so clearly in the ERA-40 vertical wind field (Fig. 8h) where a higher phase lag is present since deep convection is maximum at 0000 UTC and convection in the SHL north of $30^{\circ} \mathrm{N}$ occurs at 1200 UTC.

During the preonset period, deep convection is located at $5^{\circ} \mathrm{N}$ and is maximum at 1200 UTC whereas similarly to the postonset period the maximum of the southern subsiding branch of the Hadley-type circulation is located near $5^{\circ} \mathrm{S}$ at $1800 \mathrm{UTC}$ (Fig. 8e). These features are found in both NCEP-DOE and ERA-40 reanalyses (Fig. 8g). Figure 8c shows that the second dominant mode mainly contributes to convection enhancement south of $5^{\circ} \mathrm{N}$ at 1200 UTC and convection inhibition at $10^{\circ} \mathrm{N}$ at $1800 \mathrm{UTC}$ in May and June. The 12-h lag between convection in the ITCZ (at 1200 UTC) and in the SHL region between $15^{\circ}$ and $20^{\circ} \mathrm{N}$ (at 1200 UTC) is still present in the NCEP-DOE vertical wind field during the premonsoon period but not in the ERA-40 reanalysis (Fig. 8g).

A similar analysis has been performed on the vertical wind field at $850 \mathrm{hPa}$ where dry convection is most pronounced (Fig. 9). As for the vertical wind at $400 \mathrm{hPa}$, the influence of the first mode on the mean wind field is dominant during the postonset period (Fig. 9b) while it is very weak before the monsoon onset (Fig. 9a).
Conversely, the influence of the second mode is dominant during the preonset period (Fig. 9c) while it is very weak after the monsoon onset (Fig. 9d).

The diurnal cycle of the dry convection in the SHL is similar during the preonset and the postonset periods with a peak at night (0000 UTC) and the highest upward motions between 0000 and 0600 UTC consistently with the nocturnal jet intensification. These high upward motions values are localized at $15^{\circ} \mathrm{N}$ before $t_{0}$ and at $20^{\circ} \mathrm{N}$ after $t_{0}$ (Figs. 9e,f). This space-time variability of the dry convection in the SHL is similar between NCEP-DOE and ERA-40 reanalyses (Figs. 9g,h). During the preonset period, the second EOF mainly contributes to convection enhancement in the SHL at 0000 UTC near $15^{\circ} \mathrm{N}$ and to its maintenance (Fig. 9c). After the monsoon onset, the first dominant mode inhibits dry convection south of $15^{\circ} \mathrm{N}$ and forces upward anomalies at $20^{\circ} \mathrm{N}$ (Fig. 9b). It leads to a northward shift of the SHL from $15^{\circ} \mathrm{N}$ before $\mathrm{t}_{0}$ to $20^{\circ} \mathrm{N}$ after $t_{0}$. Comparison of the diurnal cycle of upward motions in the ITCZ (Fig. 8) and in the SHL (Fig. 9) shows that these two systems are in quadrature. In the NCEPDOE reanalyses the peaks of the diurnal cycle in the ITCZ and in the related Hadley-type circulation are the highest at 1800 UTC after $t_{0}$ (1200 UTC before $t_{0}$ ) while the peak in the SHL is at 0000 UTC. A similar quadrature is evident in ERA-40 before $t_{0}$ while the two diurnal cycles are more in phase after $t_{0}$ since the upward motions in the ITCZ is maximum at 0000 UTC.

\section{Conclusions}

The objective of his paper is to document and analyze the diurnal cycle of the WAM circulation and its seasonal evolution both in NCEP-DOE and ERA-40 reanalyses. An original methodology has been applied to the climatological mean of atmospheric fields centered around $t_{0}$, the date of the monsoon onset. It consisted of an EEOF analysis of the four daily values of atmospheric fields in order to highlight the dominant spatial and seasonal patterns of the WAM diurnal cycle. The detailed analysis of the two first leading modes reveals interesting features in both the WAM seasonal and diurnal cycles.

The seasonal cycle of the WAM has been decomposed into two distinct modes of variability:

- The dominant mode characterizes the progressive installation in July-August of the Hadley-type circulation with deep convection around $10^{\circ} \mathrm{N}$ surrounded by two subsiding branches at $5^{\circ} \mathrm{S}$ and at $25^{\circ} \mathrm{N}$. This circulation is maximum in July and August and shows a distinct diurnal cycle. It is maximum during daytime 
(a) W850 PC1 (t0-60d $-->$ to)

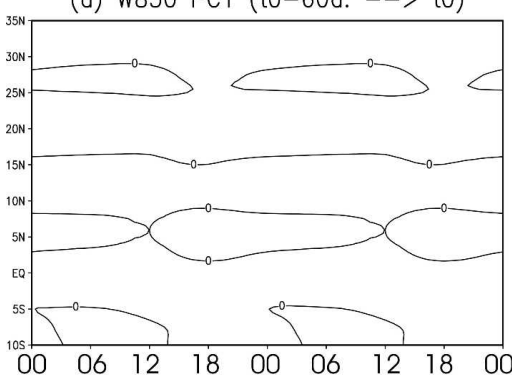

(c) W850 PC2 (t0-60d. $-\rightarrow$ t0)

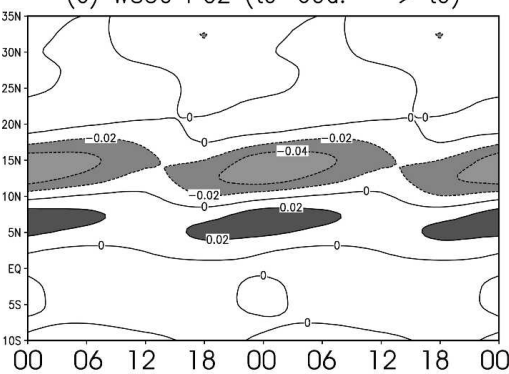

(e) W850 NCEP mean (t0-60d. $-->$ t0)

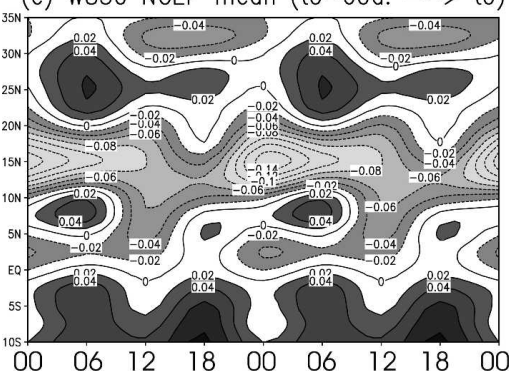

(g) W850 ERA40 mean (t0-60d. $-->$ t0)

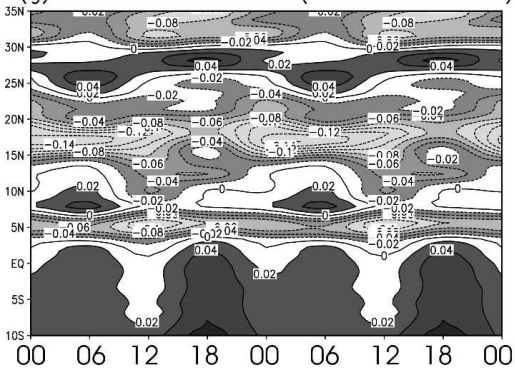

(b) W850 PC1 (to $-->$ t0 $+60 \mathrm{~d}$ )

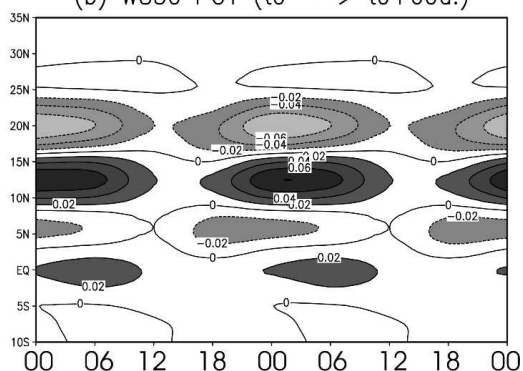

(d) W850 PC2 (t0 $-->$ t0+60d.)

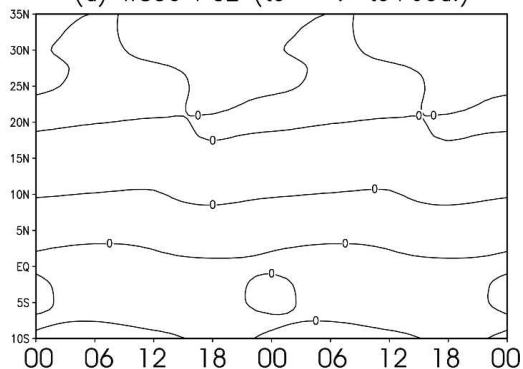

(f) W850 NCEP mean (t0 $-->$ t0+60d.)

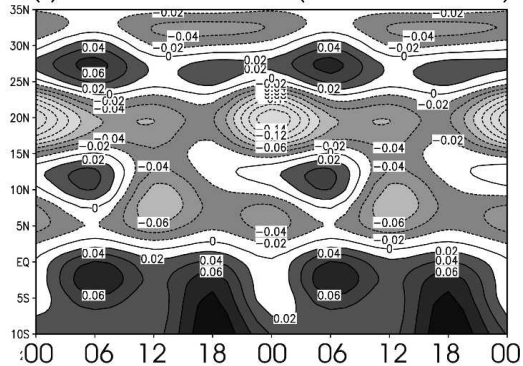

(h) W850 ERA40 mean (t0 $-->$ t0+60d.)

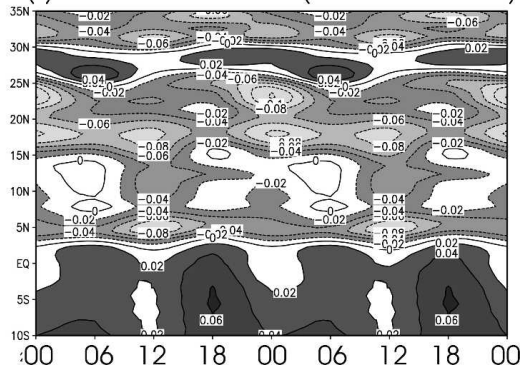

FIG. 9. Same as in Fig. 8, but for the vertical wind velocity at $850 \mathrm{hPa}$.

(1800 UTC in NCEP-DOE reanalysis) and minimum at night (0600 UTC in NCEP-DOE reanalysis). In the lower levels, it is associated with an intensification of the southwesterly winds between $15^{\circ}$ and $20^{\circ} \mathrm{N}$ and dry convection at $20^{\circ} \mathrm{N}$ overnight.

- The second mode mainly describes the onset stage of the monsoon. The SHL circulation with strong southwesterly winds between $10^{\circ}$ and $15^{\circ} \mathrm{N}$ and dry convection at $15^{\circ} \mathrm{N}$, maximum at night $(0000$ and
0600 UTC in both NCEP-DOE and ERA-40 reanalyses), is very active during May and June. This mode is coherent with the results of Sultan and Janicot (2003) showing that the two months preceding the monsoon onset are characterized by a strong influence of the SHL dynamics controlling the circulation in the low and midlevels. After the monsoon onset, this circulation weakens substantially leading to a northward shift of deep convection from $5^{\circ}$ to $10^{\circ} \mathrm{N}$. 
In the lower levels, the main feature of the diurnal cycle of the monsoon is the nocturnal jet already studied in August 2000 by Parker et al. (2005). In both the ERA-40 and NCEP-DOE reanalyses, the monsoon winds are the strongest at night and the weakest during the day. The nocturnal jet experiences a seasonal northward migration. The northward progression appears to be faster after the monsoon onset and is associated with nocturnal jet intensification. The origin of such a diurnal cycle of the low-level winds is known (but only recently investigated at such large spatial scales). During the day, convective turbulent mixing is large, whereas in late afternoon, radiative cooling inhibits thermal turbulence so the surface pressure gradient imposed by the SHL induces a geostrophic response of the winds accelerating toward low pressure, thus forming the nocturnal jet (Blackadar 1957). As the composite approach smoothes the details of the synoptic features and introduces some noise induced by the uncertainty of few days in the detection of the WAM onset, the present study cannot go further in the understanding of the processes linking the SHL, the nocturnal jet, and the northward migration of the ITCZ. Such processes should be analyzed through case studies using for instance the four atmospheric soundings per day in West Africa performed during the intensive field experiment of the African Monsoon Multidisciplinary Analyses (AMMA) program in 2006.

In the upper levels, the maximum of upward motions in the ITCZ is followed $12 \mathrm{~h}$ later by an ascent anomaly in the SHL region. This interaction may be caused by the strong ascending motion in the ITCZ generating a gravity wave that propagates northward and reaches the SHL region $12 \mathrm{~h}$ later (Peyrille and Lafore 2007). This 12-h lag between upward motions in the ITCZ and in the SHL region can be seen in NCEP-DOE reanalyses and less clearly in ERA-40 reanalyses before and after the monsoon onset.

The diurnal cycle of vertical velocity in the deep convection area appears to be different in NCEP-DOE and ERA-40 reanalyses. NCEP-DOE (ERA-40) reanalysis shows a distinct diurnal cycle of deep convection in the ITCZ with a peak of upward motions at 1800 UTC (0000 UTC) in July and August. Before the monsoon onset, the diurnal cycle of NCEP-DOE and ERA40 deep convection peaks at 1200 UTC. Yang and Slingo (2001) constructed a climatology of the diurnal cycle of convection using brightness temperatures data from multiple satellites. They showed that deep convection over Central Africa $\left(0^{\circ}-15^{\circ} \mathrm{N}, 15^{\circ}-35^{\circ} \mathrm{E}\right)$ in summer (June-August) develops in late afternoon and reaches a maximum in the evening. Mohr (2004) found a similar diurnal peak (between 1400 and 1800 UTC) in summer over West Africa using the Tropical Rainfall Measuring Mission (TRMM) satellite data. The NCEP-DOE diurnal cycle of summer deep convection in the ITCZ over West Africa seems closer to that retrieved by satellite observations. This validation should be explored further as we do not directly compare the same two variables with large-scale upward motions in one case and satellite cloudiness in the other case.

As the causes of these discrepancies are multiple, it is very difficult to explain why a variable differs from one reanalysis to another. It is especially true for variables such as vertical velocity, which cannot be validated by observational data. At this stage, we cannot argue that one reanalysis dataset is better than the other. However, the fact that there are differences between NCEP-DOE and ERA-40 reanalysis datasets is important information for this and further studies. Indeed, the use of the two reanalysis datasets is useful to provide a degree of uncertainty in the results while studying time scales or areas where validation and/or assimilated data are low. It leads to the primary constraint in understanding the dynamics of the WAM, already raised by Parker et al. (2005) and many other studies, which is the lack of direct observational data as upperair observations and surface data at high temporal and spatial resolutions. The use of only four values per day to describe the diurnal cycle is one of the main limitations of the present study as a variability at higher frequency (such as the semidiurnal cycle of the surface pressure; Dai and Wang 1999) can be mixed into the diurnal cycle. The intensive field experiment of the AMMA program during the summer of 2006 provides suitable in situ data to better sample the diurnal cycle of this monsoon system.

Acknowledgments. We are thankful to S. Ragoonathsing and G. Stern for their help in analyzing the NCEPNCAR reanalysis dataset. We thank also the two reviewers for clarifying the first draft. Based on the French initiative, AMMA was built by an international scientific group and is currently funded by a large number of agencies, especially from France, the United Kingdom, the United States, and Africa. It has been the beneficiary of a major financial contribution from the European Community's Sixth Framework Research Programme. (Detailed information on scientific coordination and funding is available on the AMMA International Web site http://www.amma-international.org.)

\section{REFERENCES}

Baron, C., B. Sultan, M. Balme, B. Sarr, T. Lebel, S. Janicot, and M. Dingkuhn, 2005: From GCM grid cell to agricultural plot: 
Scale issues affecting modelling of climate impact. Philos. Trans. Roy. Soc. London, 360B (1463), 2095-2108.

Betts, A. K., M. Zhao, P. A. Dirmeyer, and A. C. M. Beljaars, 2006: Comparison of ERA40 and NCEP/DOE near-surface data sets with other ISLSCP-II data sets. J. Geophys. Res., 111, D22S04, doi:10.1029/2006JD007174.

Blackadar, A. K., 1957: Boundary layer wind maxima and their significance for the growth of nocturnal inversions. Bull. Amer. Meteor. Soc., 38, 283-290.

Dai, A., and J. Wang, 1999: Diurnal and semi-diurnal tides in global surface pressure. J. Atmos. Sci., 56, 3874-3891.

D'Amato, N., and T. Lebel, 1998: On the characteristics of the rainfall events in the Sahel with a view of the analysis of climatic variability. Int. J. Climatol., 18, 955-974.

Dell'Aquila, A., V. Lucarini, P. M. Ruti, and S. Calmanti, 2005: Hayashi spectra of the northern hemisphere mid-latitude atmospheric variability in the NCEP-NCAR and ECMWF reanalyses. Climate Dyn., 25, 639-652.

Diedhiou, A., S. Janicot, A. Viltard, P. de Felice, and H. Laurent, 1999: Easterly wave regimes and associated convection over West Africa and the tropical Atlantic: Results from NCEP/ NCAR and ECMWF reanalysis. Climate Dyn., 15, 795-822.

Drobinski, P., B. Sultan, and S. Janicot, 2005: Role of the Hoggar Massif on the West African Monsoon onset. Geophys. Res. Lett., 32, L01705, doi:10.1029/2004GL020710.

Duvel, J. P., 1990: Convection over tropical Africa and the Atlantic Ocean during northern summer. Part II: Modulation by easterly waves. Mon. Wea. Rev., 118, 1855-1868.

Farge, M., 1992: Wavelet Transform and their application to turbulence. Rev. Fluid Mech., 24, 395-457.

Folland, C. K., T. N. Palmer, and D. E. Parker, 1986: Sahel rainfall and worldwide sea temperature 1901-1985. Nature, 320, 602607.

Hastenrath, S., 1995: Climate Dynamics of the Tropics. Kluwer, $488 \mathrm{pp}$.

Hodges, K. I., and C. D. Thorncroft, 1997: Distribution and statistics of African mesoscale convective weather systems based on the ISCCP METEOSAT imagery. Mon. Wea. Rev., 125, 2821-2837.

Janicot, S., S. Trzaska, and I. Poccard, 2001: Summer Sahel-ENSO teleconnection and decadal time scale SST variations. Climate Dyn., 18, 303-320.

Kalnay, E., and Coauthors, 1996: The NCEP/NCAR 40-Year Reanalysis Project. Bull. Amer. Meteor. Soc., 77, 437-471.

Kanamitsu, M., W. Ebisuzaki, J. Woollen, S.-K. Yang, J. J. Hnilo, M. Fiorino, and G. L. Potter, 2002: NCEP-DOE AMIP-II Reanalysis (R-2). Bull. Amer. Meteor. Soc., 83, 1631-1643.

Kutzbach, J. E., 1967: Empirical eigenvectors of sea-level pressure, surface temperature and precipitation complexes over North America. J. Appl. Meteor., 6, 791-802.

Laing, A. G., and J. M. Fritsch, 1993: Mesoscale convective complexes in Africa. Mon. Wea. Rev., 121, 2254-2263.

— tive complexes. Quart. J. Roy. Meteor. Soc., 123, 389-405.

Lamb, P. J., 1978a: Large scale tropical surface circulation patterns associated with Subsaharan weather anomalies. Tellus, 30, 240-251.

_ 1978b: Case studies of tropical Atlantic surface circulation patterns during recent sub-Saharan weather anomalies: 1967 and 1968. Mon. Wea. Rev., 106, 482-491.

Le Barbé, L., T. Lebel, and D. Tapsoba, 2002: Rainfall variability in West Africa during the years 1950-90. J. Climate, 15, 187202.

Lebel, T., F. Delclaux, L. Le Barbé, and J. Polcher, 2000: From GCM scales to hydrological scales: Rainfall variability in West Africa. Stoch. Environ. Res. Risk Assess., 14, 275-295.

Liebmann, B., and C. A. Smith, 1996: Description of a complete (interpolated) outgoing longwave radiation dataset. Bull. Amer. Meteor. Soc., 77, 1275-1277.

Mathon, V., and H. Laurent, 2001: Life cycle of Sahelian mesoscale convective cloud systems. Quart. J. Roy. Meteor. Soc., 127, 377-406.

Mohr, K. I., 2004: Interannual, monthly, and regional variability in the wet season diurnal cycle of precipitation in sub-Saharan Africa. J. Climate, 17, 2441-2453.

Ouergli, A., and P. De Felice, 1997: Wavelet transform technique to study the behavior of the 10-20-day and 25-50-day modes during Indian summer monsoon. Meteor. Atmos. Phys., 63, 171-178.

Parker, D. J., and Coauthors, 2005: The diurnal cycle of the West African monsoon circulation. Quart. J. Roy. Meteor. Soc., 131, 2839-2860.

Peyrille, P., and J.-P. Lafore, 2007: An idealized two-dimensional framework to study the West African monsoon. Part II: Large-scale advection and the diurnal cycle. J. Atmos. Sci., in press.

Racz, Z., and R. K. Smith, 1999: The dynamics of heat lows. Quart. J. Roy. Meteor. Soc., 125, 225-252.

Reed, R. J., D. C. Norquist, and E. E. Recker, 1977: The structure and properties of African wave disturbances as observed during Phase III of GATE. Mon. Wea. Rev., 105, 317-333.

Rotunno, R., 1983: On the linear theory of the land and sea breeze. J. Atmos. Sci., 40, 1999-2009.

Rowell, D. P., 2001: Teleconnections between the Tropical Pacific and the Sahel. Quart. J. Roy. Meteor. Soc., 127, 1683-1706.

— C. K. Folland, K. Maskell, and M. N. Ward, 1995: Variability of summer rainfall over Tropical North Africa (1906-1992): Observations and modelling. Quart. J. Roy. Meteor. Soc., 121, 669-704.

Schubert, S. D., H. M. Helfand, C. Wu, and W. Min, 1998: Subseasonal variations in warm-season moisture transport and precipitation over the central and eastern United States. $J$. Climate, 11, 2530-2555.

Simmons, A. J., and J. K. Gibson, 2000: The ERA-40 project plan. ERA-40 project Rep. Series 1, ECMWF, Shinfield Park, Reading, United Kingdom, 63 pp.

Sterl, A., 2004: On the (in-)homogeneity of reanalysis products. $J$. Climate, 17, 3866-3873.

Sultan, B., and S. Janicot, 2003: The West African monsoon dynamics. Part II: The "preonset" and "onset" of the summer monsoon. J. Climate, 16, 3407-3427.

Torrence, C., and G. P. Compo, 1998: A practical guide to wavelet analysis. Bull. Amer. Meteor. Soc., 79, 61-78.

Ward, M. N., 1998: Diagnosis and short-lead time prediction of summer rainfall in tropical North Africa at interannual and multidecadal timescales. J. Climate, 11, 3167-3191.

Weare, B. C., and J. S. Nasstrom, 1982: Examples of extended empirical orthogonal function analyses. Mon. Wea. Rev., 110, 481-485.

Yang, G.-Y., and J. Slingo, 2001: The diurnal cycle in the Tropics. Mon. Wea. Rev., 129, 784-801. 